Revista de la red interuniversitaria de estudios sobre las literaturas rioplatenses contemporáneas en Francia

21 | 2020

Glosolalias transplatinas: fantasmas, utopías y ficciones lingüísticas

\title{
La línea pseudoalfabética: apuntes sobre lo ilegible en Mirtha Dermisache y León Ferrari
}

La ligne pseudo-alphabétique: notes sur l'illisible chez Mirtha Dermisache et León Ferrari

The Pseudo-Alphabetical Line: Notes on the Unreadable in Mirtha Dermisache and León Ferrari

Julio Prieto

\section{(2) OpenEdition}

\section{Journals}

Electronic version

URL: http://journals.openedition.org/lirico/9627

DOI: $10.4000 /$ lirico.9627

ISSN: 2262-8339

Publisher

Réseau interuniversitaire d'étude des littératures contemporaines du Río de la Plata

Electronic reference

Julio Prieto, «La línea pseudoalfabética: apuntes sobre lo ilegible en Mirtha Dermisache y León Ferrari», Cuadernos LIRICO [En línea], 21 | 2020, Publicado el 12 julio 2020, consultado el 29 enero 2021. URL: http://journals.openedition.org/lirico/9627 ; DOI: https://doi.org/10.4000/lirico.9627

This text was automatically generated on 29 January 2021.

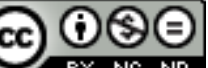

Cuadernos LIRICO está distribuido bajo una Licencia Creative Commons Atribución-NoComercialSinDerivar 4.0 Internacional. 


\title{
La línea pseudoalfabética: apuntes sobre lo ilegible en Mirtha Dermisache y León Ferrari
}

\author{
La ligne pseudo-alphabétique: notes sur l'illisible chez Mirtha Dermisache et \\ León Ferrari \\ The Pseudo-Alphabetical Line: Notes on the Unreadable in Mirtha Dermisache \\ and León Ferrari
}

Julio Prieto

1 Retomando el lema horaciano ut pictura poesis -de hecho, invirtiéndolo- el historiador del arte Michael Baxandall observa que la pintura renacentista toma como modelo el patrón retórico del "período" en la oratoria clásica y humanística - "the pattern of the grand neoclassical phrase" (100-101). A partir de esta idea, se diría que la historia del arte moderno es la historia de la pérdida de cohesión del paradigma de la frase clásica un específico modelo de legibilidad y visión del mundo que está directamente ligado al desarrollo de la perspectiva en el arte del Renacimiento. Podríamos describir esa historia como un sistema de desvíos, cortocircuitos y derivas de ese paradigma retórico y estético que informa todo un sistema político y económico, en la medida en que podemos relacionarlo con los orígenes del Estado moderno y con la historia del capitalismo y el colonialismo europeo. Así, en vez de un arte que emula la transparencia y fluidez de la frase clásica, tenemos una serie de prácticas artísticas que problematizan ese paradigma y ensayan distintas formas de coagulación o enturbiamiento de la frase, cultivando trasuntos plásticos del anacoluto, la tautología, la catacresis y otras figuras retóricas defectivas que a efectos de este análisis podríamos llamar "técnicas de contradicción". En ese sentido, podrían estudiarse por ejemplo las correspondencias entre los Disparates o los Caprichos de Goya y los ejercicios de los escritores absurdistas ingleses -los limericks de Edward Lear, el "Jabberwocky" de Lewis Carroll-, entre otros episodios de cortocircuito semántico que jalonan la historia del arte y la literatura moderna. Si ésta es en gran medida la historia de una gradual reducción sémica que acompaña el paso de la época del "mundo-libro" a la época del "libro vacío" ${ }^{-l a}$ época 
de la "ilegibilidad del mundo" que definiría la modernidad (Blumenberg 1981)-, esta tendencia llega a su apogeo en el contexto de las vanguardias y neovanguardias del siglo XX, por una combinación de factores en la que más allá de la evolución específica del arte occidental intervienen una serie de acontecimientos históricos que contribuyeron a agudizar la erosión de los paradigmas de sentido dominantes -las dos guerras mundiales y las matanzas masivas del nazismo y el estalinismo, entre otros (Steiner 1976: 14-15).

2 En este contexto de crisis de los paradigmas de legibilidad establecidos, y entre los muchos procedimientos de reducción sémica que el arte del siglo XX opone al cultivo de la "gran frase (neo)clásica", me quiero detener aquí en uno de los más notables: lo que podríamos llamar el repertorio de la línea pseudoalfabética. Se trata de una serie de prácticas que oscilan entre la literatura, la poesía visual y las artes plásticas, y que exploran el espectro de los lenguajes hipotéticos, inventados o imaginarios en su forma más evanescente, produciendo una serie de experiencias semióticas en infrarrojo que ponen continuamente en juego lo que en términos de Foucault llamaríamos el vínculo "infinito" entre lo legible y lo visible (1968: 19). En vez del período o la frase (neo)clásica, ahora el elemento productivo es la línea "pseudoalfabética" -la línea en cuanto elemento textual o unidad semiótica reducida a su visualidad y a su materialidad, movilizada en un parpadeante umbral entre la (esfumada) promesa de sentido y la performatividad de un acto verbal indiscernible. En vez del discurso, se pone de relieve la escritura en cuanto inscripción -lo que Barthes llamaría la scription (2006: 6)-; en vez de la profundidad del enunciado y la casuística de la interpretación, el gozo de la escritura -la jouissance del trazo- y la extensión de la enunciación en cuanto potencia de sentido. Al suspenderse la conversión del lenguaje en discurso -lo propio de la enunciación de acuerdo con Benveniste (1974: 79)- lo que se acentúa son sus circunstancias externas o materiales, su capacidad de proyección: la escritura, vale decir, cobra relieve como acción corporal y como gesto inventivo, intervención gozosa de la línea donde el ojo y la mano tienen precedencia sobre la razón del lenguaje -el verbo en un sentido metafísico y en el literalmente físico de lo ligado a la boca, al órgano de fonación que se pone en juego al hablar.

3 Los diversos experimentos con la línea pseudoalfabética que emergen en las primeras décadas del siglo XX en el contexto de las vanguardias históricas -en una serie de prácticas más o menos interrelacionadas: las "palabras en libertad" de Marinetti, los collages cubistas y dadaístas, las pinturas de signos flotantes de Paul Klee y Joan Miró, las étendues de Henri Michaux, etc.- cobran un renovado vigor en el ámbito de las neovanguardias de los años 60 y 70, en una serie de movimientos y prácticas igualmente interrelacionadas: la poesía concreta brasileña, el movimiento letrista, la poesía visual de Clemente Padín y Eduardo Antonio Vigo, el arte-correo de Guillermo Deisler, los agrafismos de José-Miguel Ullán, etc. En lo que sigue me quiero detener en los "pseudoalfabetismos" de dos artistas argentinos que surgen en la efervescente escena de la neovanguardia porteña de los 60: León Ferrari (1920-2013) y Mirtha Dermisache (1940-2012).

\section{León Ferrari: la transformación de la escritura}

Los primeros experimentos de León Ferrari con la línea pseudoalfabética datan de 1962-1964. En esos tres años produce un conjunto extraordinariamente rico de dibujos 
"escriturales" a la par que una serie de estructuras escultóricas de acero -esculturas “dibujadas" (Ferrari 2005: 31)- con las que aquellos están sutilmente ligados. El núcleo generador de estas obras -tanto de los dibujos "escritos" como de las esculturas "dibujadas"- es la liberación de la línea: liberación del significado y apertura al sentido y a los sentidos ${ }^{2}$ que multiplica los pasajes entre lo legible, lo visible, lo tocable, lo audible. Los primeros dibujos, realizados a petición del galerista milanés Arturo Schwartz para la exposición L'Avanguardia internazionale (1962), revelan ya dos rasgos constantes en el trabajo de Ferrari con la abstracción: el efecto escritural y un principio de proliferación fractal por el que determinadas formas se reproducen en distintos planos y escalas (así como, más allá del dibujo, se replican en distintos medios y materiales). Uno de ellos presenta dos grupos de líneas que por momentos sugieren dos caracteres chinos fantásticamente alargados (como si dibujados por un improbable cruce de El Greco y Paul Klee) [fig. 1]. Este patrón rectangular que podría ser una letra o ideograma de una lengua desconocida (acaso una lengua oriental) se repite con distintas variaciones en una serie de dibujos pseudo-escriturales -tanto en aquellos donde el efecto de escritura es más patente, por combinar lo que parecen ser signos alfabéticos o ideográficos en renglones regulares, como en otros que se dirían a medio camino entre lo escritural y lo pictórico [fig. 2]. En estos últimos el efecto escritural es notoriamente evanescente, hasta el punto de ser apenas perceptible y casi desaparecer del todo en algún caso, al prescindir de los renglones y sugerir distintos efectos pictóricos: en uno de ellos, el arremolinamiento de las líneas en cúmulos arborescentes y el juego con los llenos y los vacíos sugieren la delicada textura de un paisaje brumoso a la manera de los grabados de Hokusai (o lo que podría ser la idea de un paisaje de Hokusai) [fig. 3], en tanto que en otros el caótico entrecruzamiento de líneas en múltiples direcciones y el uso de tintas de distintos colores (así como los manchurrones de tinta derramada) recuerdan las propuestas del expresionismo abstracto y en particular el action painting de Jackson Pollock, un efecto aún más evidente en los "cuadros escritos" de los 80 y los 90, por la ampliación del formato y el uso de técnicas pictóricas propiamente dichas (acrílico y pastel). De hecho, aunque no dejen de apelar a la escritura, estos son casi los únicos cuadros pintados que propone la obra de Ferrari, que sobre todo se compone de dibujos, esculturas, montajes e instalaciones de diversa índole -de modo que, a partir de Pollock, pero poniendo en deriva la matriz pictórica, se diría que lo que propone el artista argentino es una multiforme práctica de action writing.

5 La exploración de la línea pseudoalfabética en estos años adopta una forma particularmente intrigante en la serie de las "escrituras deformadas", una serie de dibujos realizados en 1963-64 en los que frases o palabras copiadas a mano se deforman hasta producir una caligrafía ilegible. Algunas de estas caligrafías deformes producen un efecto de estatismo y gravidez, como si se tratara de líneas de palabras estancadas que, fuera de uso, hubieran sido invadidas por hongos y telarañas; otras, entre las que cabe incluir las famosas "cartas a un general", sugieren un nervioso dinamismo que evoca emociones negativas (inquietud, rabia, desesperación) acordes con la dimensión de denuncia política que proyecta el título en las tres versiones de Carta a un general [figs. 4 y 5]. En uno de sus cuadernos de trabajo, en una hoja fechada el 31-1-63, Ferrari trabaja con esa técnica de deformación la frase "quisiera decirte cuando te vea que no puedo", la cual aparece debajo de un fragmento de escritura ilegible que sugiere una fantástica mezcla de caracteres latinos y arábigos -una mutación caligráfica en la que es posible reconocer con algún esfuerzo la frase citada (2005: 86). Este fragmento 
parecería proponer una clave de desciframiento, pero de hecho tiene más interés desde el punto de vista de la génesis de esa escritura. Pues si a la manera de Champollion quisiéramos utilizarlo como una suerte de piedra rosetta para descifrar los dibujos escritos en esa extraña caligrafía pseudoaljamiada, nuestras expectativas se verían perfectamente frustradas: salvo en una de las versiones de Carta a un general (en la que puede reconocerse tres veces la palabra "general"), apenas si es posible distinguir en ellos alguna que otra letra desperdigada. Antes que como clave de desciframiento, esa frase viene a funcionar entonces como clave metapoética que ilumina la lógica de producción de estos "dibujos escritos" así como en general la práctica artística de Ferrari en su varia invención pseudoalfabética. En su diversa exploración de lo ilegible, en las transformaciones de la escritura, lo que está siempre en juego es un pensamiento del "no poder" del lenguaje y los sistemas y medios de comunicación establecidos -lo que implica tanto exponer una impotencia como abrir el horizonte de una potencia futura, de algo aún no cumplido en el lenguaje-, pensamiento que emerge precisamente por la puesta en suspenso del decir y del ver, en el trabajo con los modos hipotéticos o desiderativos de un decir o un ver en potencia ${ }^{3}$. En efecto, y nada más exacto para describir lo que hacen estos dibujos y en general el arte analfabético de Ferrari: "quisiera decirte cuando te vea que no puedo".

Por estos años Ferrari realiza también la serie de los "manuscritos" (1964-65) -textos de diversa índole transcritos a mano, que resaltan de distintas maneras la visualidad de la letra y que se diría que trabajan la ilegibilidad por vías "alfabéticas". En cuanto ejercicios de legibilidad desviada, los "manuscritos" de Ferrari comparten notorios vínculos con sus exploraciones pseudoalfabéticas, y en particular tienen en común con las "escrituras deformadas" la técnica de copiar textos a mano enfatizando el gesto caligráfico -técnica que expandida a todo tipo de materiales y superficies (maniquíes, fotografías, botellas, telas, inodoros) será a partir de entonces uno de los principales modos de producción de su obra, por lo que podemos considerar esta serie como un momento clave en el proyecto general de transformación de la escritura que ésta pone en juego.

7 En principio, estos "manuscritos" se escriben en una lengua reconocible (el castellano) y se pueden leer, pero en ellos lo legible experimenta una serie de interrupciones y derivas que hacen emerger de manera perturbadora lo visible de la escritura, poniendo en cuestión su legibilidad. El trabajo de una continua fricción entre el ver y el leer tiene su forma más extrema en Cuadro escrito (1964), empezando por la paradoja que plantea el título. Este "manuscrito" plantea de manera emblemática una problematización de la lectura que emerge por la pictorialización de la escritura, de modo que el "manuscrito" deviene "cuadro" -un cuadro imposible, que en una suerte de auto-ékfrasis defectuosa da a ver la escritura, la descripción de lo que (no) dibuja [fig. 6]. La problematización de lo legible en estos "manuscritos" no sólo tiene una dimensión gráfica y material que atañe al "dibujo" de la escritura, sino también una dimensión léxico-sintagmática y discursiva que implica una específica deriva semántica. Esta empieza por el indecidible estatuto de lo que se da a leer (a la vez que a ver) -en este caso, la imposible descripción de un cuadro que no se puede pintar, que por momentos deriva hacia una intermitente micronarrativa autodeíctica en la que es central la invisibilización del significado:

[...] y precisamente en este lugar empezaría una línea delgada flaca ya con la intención de cubrirla después maniobrando con la transparencia. [...] y también un sospechado sugerido significado opaco bajo el barniz, no simbólico, como para que al verlo alguien ni siquiera se dé cuenta que en sus entrañas se refriega 
preguntándose cuál es el significado de ese caballo blanco veloz hacia el monte de Venus [...]. Pero ese significado debe ser inexistente por verdadero y ni la más mínima sospecha de certidumbre debe ser engendrada en los ojos que miran. (2005: 292)

8 En esta deriva del sentido por la que la escritura -el discurrir de las líneas- se abre a rumbos desconocidos no se trata tanto de una ausencia de significado -"inexistente por verdadero"- cuanto de su apertura a un devenir corporal: el sentido no es aquí algo que apela a la razón, a la lógica del discurso, sino que pasa por el cuerpo -literalmente, es lo que "se refriega en las entrañas". Esa productiva pérdida de sentido, por la que la escritura inicia un devenir visual-material-corporal, se da en otros casos como resignificación de textos sacados de contexto, como cuando en Buenas versiones (1964) se transcriben literalmente dos fragmentos de noticias del diario La Nación, en un gesto equiparable a los détournements situacionistas y a ciertas formas contemporáneas de escritura "conceptual" (Dworkin/Goldsmith; Perloff). Más a menudo, va ligada al cultivo del absurdismo verbal y la glosolalia, a la manera de las jitanjáforas de Mariano Brull, el "Jabberwocky" de Carroll o el "glíglico" de Cortázar. El cultivo del sinsentido suele conllevar el erotismo, la aparición del cuerpo y la jouissance de la lengua, tanto en las prácticas glosolálicas y en las poéticas "deslenguadas" que les son afines (así en el Girondo de En la masmédula o en la poesía de Perlongher) como en las lenguas inventadas (como el "neocriollo" de Xul Solar). Así también en estos "manuscritos". Valga de muestra un botón, notable por la manera en que la deriva semántica de la glosolalia se vincula con un aprendizaje otro -un aprendizaje corporal- del "alfabeto y la sintaxis":

Cuando entré en la casa Alafia estaba jabalconeándose al impiadoso gazafatón añojada envedijada entre la estornija y la jámila que se avezó en mis abriles, atragantándome con el primer vaso miré ya en la segunda puerta como un ajonje horrorosamente jinjallado el jallullo se desenvelejaba balanceando suavemente el igorrote y su corbachada gritándome: Lampuga jarújate un margoso te acordás la máchiga corcusida enallardando un convólvulo cispadano desmogado en el merco lilaila se entreveró con el jesuato sacristán de San Telmo allí nomás los podés ver en el refaladero con las jámbicas y la macsura, maldita corcusida confesándose al mismo ritmo de la empapujadura y simultáneamente con su abarraganado jesuato que olfatea las huellas de su holotúrico mastigador. Me quedé latebroso: la corcusida me gustaba, con ella me había ido a los sauces años atrás antes de conocerla a Alafia y fue con ella que aprendí todo el alfabeto y la sintaxis. (2005: 287-88)

9 A mediados de los 70 Ferrari retoma la abstracción de los dibujos escritos y las esculturas de acero, y en general la exploración de la línea pseudoalfabética, tras una década de abandono del arte "no significativo" en aras de la lucha política (Ferrari 2005: 99), una etapa que se inicia con La civilización occidental y cristiana (1966) y en la que participa en distintos proyectos y acciones colectivas -Tucumán arde (1968), Malvenido Rockefeller (1969), Experiencias visuales (1971)- y que culmina en 1976 con su exilio en Brasil, donde residirá quince años (Pérez-Oramas 35-36). De particular interés, por la novedad que representa en el espectro de los dibujos escritos y las exploraciones pseudoalfabéticas, es la serie de los "vocabularios" y los "códigos" realizada en 1979. Se trata de una serie de doce dibujos donde el principio de fuga rizomática y proliferación continua de la línea a partir de la horizontalidad de la escritura indoeuropea -el patrón predominante en los dibujos escritos de los años $60-$ da paso a una nítida estructuración de líneas discontinuas, verticales y paralelas que se agrupan formando imaginarias letras o ideogramas dispuestos en hileras regulares. Aunque estos 
"códigos" y "vocabularios" no son menos ilegibles que las caligrafías imaginarias de los 60 , a primera vista producen una impresión de orden y claridad que contrasta con los efectos de enmarañamiento y confusión caótica a que aquellas son propensas. De hecho, un primer rasgo a destacar en estos dibujos es el irónico remedo de la claridad didáctica de los diccionarios y diagramas científicos, y la irrupción de una suerte de humorismo semiológico -algo que, con distintos acentos, ya aparecía en parte en los "manuscritos".

10 Podemos distinguir cuatro subgrupos dentro de esta serie: los "vocabularios teóricos" (las dos versiones de Vocabulario y el dibujo titulado Mensaje), los "vocabularios eróticos" (las tres versiones de Kama-Sutra), los "códigos" (los cuatro dibujos titulados Código de señales secretas, Código, Diccionario 79 y Zoología) y las "traducciones" (integrado por un dibujo sin título y otro titulado Traducciones) [figs. 7 y 8]. El primer subgrupo propone tres vocabularios o alfabetos imaginarios (o bien dos "vocabularios" o "alfabetos", y un "mensaje" compuesto con los signos que proponen aquellos), a partir de un patrón de líneas verticales paralelas que se repite regularmente con mínimas variantes, formando rectángulos que sugieren hipotéticas letras, palabras o ideogramas. En estos tres dibujos podemos observar ya dos elementos presentes en toda la serie: el sutil zoomorfismo de los signos, que por momentos cobran vida y sugieren gestos o acciones animales o humanas, y -directamente relacionado con estola introducción de flagrantes perturbaciones del orden propuesto que en última instancia cortocircuitan la lógica del sistema.

11 En cuanto al primer punto, podríamos comparar estos "vocabularios" con la semiosis antropomórfica que propone Ni mú (2002), el libro de poesía visual del español JoséMiguel Ullán, integrado por diez páginas de imaginarias letras o ideogramas humanoides (veinticinco por página, en disposición idéntica a la del segundo Vocabulario de Ferrari) [fig. 9]. Las letras mudas de Ullán -que a fuer de ilegibles, y como es de rigor en toda escritura imaginaria, no dicen "ni mú"-, proponen formas antropoides con un marcado sesgo expresionista que por momentos deviene goyesco; las de Ferrari destacan en cambio por la economía expresiva con que a través de mínimas variaciones en un patrón abstracto logran evocar acciones, movimientos y emociones más o menos humanas (así podemos ver o leer en estos "vocabularios" gestos o signos que harían las veces de palabras como "sorpresa", "indignación", "aburrimiento", etc.). De hecho, y pasando al segundo punto, lo más sorprendente (e inquietante) es que en algunos casos los signos interactúan en parejas. En el primer Vocabulario vemos dos signos armónicamente unidos (dos signos amantes) y otros dos unidos en disarmonía (dos signos que riñen), y aun otros dos que se dan la espalda o bien se encaran desafiantes; en el segundo Vocabulario, vemos un signo gritándole a otro (o tal vez dándole una bofetada), un signo indiscreto que escandaliza con sus chismes a su interlocutor, otro abrumado por la egocéntrica exuberancia de su vecino... Lo cual, aparte de introducir amagos de peripecias micronarrativas y cómicos lances que atentan contra la neutra funcionalidad del vocabulario, plantea la duda de si esas parejas son dos signos esporádicamente unidos o bien uno formado por esa relación -lo que de inmediato contamina de inverosimilitud a todo el conjunto, pues si se trata de signos dobles nos preguntamos qué otros signos dobles (o triples), qué otras relaciones entre los signos estamos dejando de ver. El hipotético principio de significación de este vocabulario se desliza hacia lo indecidible, al ser imposible determinar cuáles serían sus unidades mínimas -algo así como si no pudiéramos determinar si las letras A y B del 
alfabeto latino son dos letras o bien la letra $\mathrm{AB}$ o $\mathrm{ABC}$ o $\mathrm{ABCD}$, etc., o bien (si pensamos en un lenguaje ideogramático como el chino) como si no pudiéramos determinar si los signos designan palabras o frases, con lo cual en vez de ante un "vocabulario" bien pudiera ser que estuviéramos ante un poema, una novela, un tratado de agronomía... o algún otro tipo de "mensaje", como lo sugiere el título del tercer "vocabulario".

La perversión del principio de legibilidad del sistema es aún más patente en los dibujos que integran la subserie de los "códigos" y "diccionarios", que imaginan alfabetos heterotópicos según la lógica de los conjuntos imposibles tan cara a Borges. En cierto modo estos dibujos combinan la delirante clasificación de los animales en la improbable enciclopedia china de "El idioma analítico de John Wilkins" con la paradoja del mapa y el territorio que propone "Del rigor en la ciencia" -un mapa que coincidiría con la totalidad del territorio y por tanto es abandonado como proyecto inútil del que restan aquí y allá melancólicos pedazos ajados. Zoología presenta un sibilino alfabeto-bestiario que propone correspondencias entre una serie de signos y figuras de animales que se dirían pintadas con el "finísimo pincel de piel de camello" de la imaginaria enciclopedia china borgeana [fig. 10]. Las correspondencias entre signos y animales se disponen en cuatro hileras horizontales según un principio cratílico de motivación mimética del lenguaje -una tradición de pensamiento lingüístico que va desde el diálogo platónico que le da nombre hasta las imaginativas reflexiones de Ezra Pound sobre los ideogramas chinos, y que Borges sintetiza en el cuarteto inicial del soneto "El Golem": "Si (como afirma el griego en el Cratilo) / el nombre es arquetipo de la cosa / en las letras de rosa está la rosa / y todo el Nilo en la palabra Nilo" (1989: 263). En cierto modo, tanto Zoología como Diccionario 79, el dibujo que hace pareja con éste, ponen de manifiesto, llevándolo al absurdo, lo monstruoso de la tesis cratílica (ya sugerido en el título del soneto borgeano): lo monstruoso, vale decir, de la idea de que todo el Nilo estuviera contenido en la palabra Nilo, la idea inconcebible y odiosa de que el lenguaje fuera una mera réplica mutante, una copia muerta (un golem) del mundo.

Cada signo en Zoología imita en principio la silueta del animal que representa, o algún rasgo descollante del mismo -la cornamenta del alce o del búfalo, las alas desplegadas del águila, la piel rayada de la cebra, etc.-, pero este principio mimético, relativamente consistente en las dos primeras hileras, degenera progresivamente por la introducción de una serie de incongruencias. Una pareja de signos lineales remeda actitudes animales, pero a imitación de dos parejas de letras góticas (dos $\mathrm{G}$ y dos $\mathrm{K}$ ), en una perversión del principio mimético que, invirtiendo las tornas, busca lo "animal" en las letras en vez de lo "lingüístico" en los animales. Parejas de animales más o menos incongruentes (un oso pardo y una sardina, una anguila y una langosta) son representadas por signos cada vez más arbitrarios, no sólo por la pérdida del parecido "natural" sino por la interferencia de otros códigos (en el ramillete de líneas correspondiente al oso-sardina se enredan diagonalmente las letras S, Y, R, P, y una de las líneas es coronada absurdamente por una solitaria letra E). Al final de este aberrante diccionario en vez de leer una equivalencia lingüística vemos un exuberante paisaje selvático: las líneas del último "signo" monstruosamente alargadas hasta invadir la hilera superior hacen las veces de ramas en las que se posan multitud de animales (palomas, monos, un buitre, una libélula) y bajo las cuales deambulan una garza, una tortuga, un alacrán y una mujer desnuda con una manzana en la mano al lado de una víbora -lo que sugiere la figura de la Eva bíblica, con el consiguiente cortocircuito simbólico que dotaría a la "víbora" y a la "mujer" de una carga significativa en un plano diferente, haciendo funcionar esas figuras como símbolos en el discurso bíblico del 
pecado original, en vez de como imágenes genéricas en un "diccionario". Es decir, en esta caprichosa "zoología" la ideología implícita a toda clasificación -en este caso, la ideología patriarcal que demoniza o animaliza a la mujer- irrumpe grotescamente arruinando la neutralidad del discurso "científico", y la pulsión (des)codificadora lleva directamente al delirio semiótico.

14 A esta sibilina irrisión de la lógica del código obedece la proliferación de interferencias que cortocircuitan su legibilidad: equivalencias espurias o autocontradictorias que, a la manera de las categorías "etcétera" o "incluidos en esta clasificación" en la apócrifa enciclopedia china borgeana, arruinan la lógica de la clasificación -y como nos lo recuerda Barthes, la clasificación es "el fundamento del signo" (1981: 17), aquello que habilita el mecanismo de la significación. En otras palabras, en los "códigos", "diccionarios" y "vocabularios" que proponen estos dibujos, es imposible concebir un orden en que pudieran coexistir todos los elementos de la serie o conjunto postulado, lo que de acuerdo con el análisis de Foucault (1968: 3) distinguiría la visión utópica de la imaginación heterotópica (la que a menudo encontramos en Borges y en Ferrari). Es decir, lo que se imagina aquí no es otro mundo, otra lengua -otro orden posible- sino la imposibilidad del orden -de todo orden. En última instancia, de lo que se trata en estas "ficciones de escritura" (Giunta 2011: 176) y en general en la obra analfabética de Ferrari es de la ilegibilidad constitutiva de toda lengua y de todo código -de todo orden semiótico establecido-, lo cual, lejos de ser una constatación fatalista, es un principio productivo de la práctica artística y una fuente de pensamiento crítico: la piedra de toque de una gnosis gráfico-textual que hace de la sospecha de la legibilidad, de la exposición de las contradicciones que sustentan todo orden -todo sistema de poder- la operación cardinal de un proyecto estético y político de transformación de la escritura -un proyecto que renueva y replantea continuamente la pregunta borgeana: “Tú, que me lees, ¿estás seguro de entender mi lenguaje?” (1989: 470).

\section{Mirtha Dermisache: el reposicionamiento de la lectura}

Hacia 1967, pocos años después de que León Ferrari iniciara las exploraciones pseudoalfabéticas que lo ocuparon entre 1962 y 1965, y en cierto modo tomando su relevo, puesto que entre 1965 y 1975 Ferrari abandonó dichas exploraciones en aras del arte comprometido que reclamaban esos años de horizontes revolucionarios, Mirtha Dermisache inicia su admirable trabajo con grafismos ilegibles. La relación entre Dermisache y Ferrari es una cuestión curiosamente poco atendida por la crítica, por más que no sea infrecuente encontrarlos reunidos en volúmenes, exposiciones y reseñas sobre arte de vanguardia, poesía visual, libros de artista, etc. (Polaschegg 2018: 176; Becerra $2018 \mathrm{Web}$; Biscia $2020 \mathrm{Web})^{4}$. Esa laguna crítica sorprende especialmente dadas las múltiples afinidades entre dos proyectos contemporáneos que surgen en un mismo contexto -la escena de neovanguardia porteña de los años $60-$ y que, en su trabajo con escrituras ilegibles, llegan a soluciones a menudo muy cercanas -o bien a planteamientos muy similares de ciertos problemas. Si bien es cierto que la exploración de la escritura ilegible tiene una larga tradición en la literatura y el arte del siglo XX desde André Masson, Henri Michaux y Christian Dotremont a una larga nómina de artistas y escritores en los años 60 y 70: Irma Blank, Guy de Cointet, Hanne Darboven, Bernard Réquichot, Mira Schendel, Roberto Elía, Margarita Paksa, José-Miguel Ullán, entre otros-, sería difícil encontrar dos artistas o escritores más cercanos en el cultivo 
de la línea pseudoalfabética -i.e. en el trabajo con lo ilegible a partir de la línea manuscrita o impresa y los formatos textuales a ella asociados.

No es tanto la cuestión de las influencias lo que me interesa indagar aquí, sino más bien las condiciones históricas de esa cercanía: las condiciones que hicieron posible la emergencia más o menos simultánea de dos proyectos tan afines como singulares y autónomos en su concepción y desarrollo. En ese sentido, no es casual el que estos proyectos surjan precisamente en Buenos Aires en los años 60, y ello no sólo por las específicas características de la neovanguardia artística argentina, con la que comparten algunos de sus rasgos más prominentes, sino sobre todo por la manera en que, más allá de ésta, ambos continúan y renuevan una específica tradición argentina de escritura y pensamiento de lo ilegible. En otras palabras, no es casual que los pseudoalfabetismos de Ferrari y Dermisache surjan precisamente allí donde se desarrolló una de las vetas más vigorosas de "escritura errante" en la tradición latinoamericana (Prieto 2016). Si estos proyectos se parecen, quisiera sugerir, no es tanto porque puedan haberse influido de una $u$ otra manera (lo que desde luego no es descartable), sino más bien por la manera en que esa tradición influye en ambos a la vez -de hecho, se diría que lo que los une, más que puntuales parecidos, son las diferentes maneras en que dialogan con esa tradición.

En su trabajo plástico pseudoalfabético Dermisache y Ferrari proponen formas de escritura expandida -de manera que, a la vez que como artistas, es posible verlos como escritores por otros medios. Si ese trabajo es indisociable del giro lingüístico de los años 60 en las artes y en las ciencias humanas, no menos decisivos son sus vínculos con las vertientes específicamente rioplatenses de ese giro, en las que revierte una rica tradición local de escrituras ilegibles. Una tradición de escritura en cuyo origen está el seminal diálogo de Macedonio y Borges en el contexto de la vanguardia argentina de los años 20 y 30, que se continúa en los años 50 en la poética glosolálica del último Girondo y se reactiva en los 60 y 70 en la poesía visual del Movimiento Diagonal Cero y en las radicales prácticas escriturales ligadas a la revista Literal (1973-1977) -y en particular en la poética de "mala escritura" de Osvaldo Lamborghini, una de sus figuras más influyentes-, las cuales a su vez reverberan en los movimientos poéticos de los 80 que reivindican una práctica del "nuevo signo" (Perednik 1981: 3) -tal la propuesta de la revista Xul (1980-1997) y del grupo porteño Paralengua-, y en el trabajo de poetas como Alejandra Pizarnik, Arturo Carrera, Emeterio Cerro o Néstor Perlongher.

Entender los pseudoalfabetismos de Dermisache y Ferrari como parte de esta tradición de escrituras "errantes" permite dar cuenta no sólo de su parecido, sino también de sus más ostensibles diferencias. Pues esos pseudoalfabetismos en cierto modo renuevan en los años 60 y 70 las líneas principales del conflictivo diálogo sobre la cuestión de lo legible que entablan Borges y Macedonio en la década del 30 (Prieto 2007). A grandes rasgos, si en las prácticas pseudoalfabéticas de Ferrari es posible reconocer una notoria decantación borgeana en el trabajo irónico con las paradojas de la reescritura y en el cultivo de un agudo sentido del humor metasemiótico -un proyecto de transformación de la escritura de inspiración heterotópica-, las escrituras ilegibles de Dermisache tal vez sean una de las más productivas actualizaciones del proyecto macedoniano de desmontaje y refuncionalización del libro -un proyecto donde la transformación de la escritura adopta un cariz marcadamente utópico.

19 A partir de aquí podríamos señalar una serie de diferencias entre los proyectos de escritura ilegible de Ferrari y Dermisache. La primera y más notoria: si en el primero el 
trabajo con la línea pseudoalfabética es una de las vertientes de una obra heterogénea que incluye un amplio abanico de prácticas, y sólo en ciertas ocasiones remite al formato libro o a categorías textuales como la carta, el diccionario, etc. -así en Libro de artista (1962), en Carta a un general o en la serie de los "códigos"-, en Dermisache dicho trabajo constituye su entera práctica artística, la cual adopta sistemáticamente la forma de libro, o en cualquier caso la de algo para ser leído (una carta, un diario, una postal, un boletín, un poema, etc.). Si bien la potencia de la escritura ilegible, en su caso como en Ferrari, radica en gran medida en su continua oscilación entre la plástica y la escritura, y en su no ser propiamente ni plástica ni escritura (Cozarinsky 1970: 51), en Dermisache hay desde el principio una intención muy clara de presentar su trabajo como un tipo de escritura que aspira a la forma de "libro", así como un rechazo explícito tanto de su conceptualización en cuanto obra plástica como de las formas de circulación de la "obra de arte" (exhibición en galerías, museos, ferias de arte etc.). Nada parecido hallamos en Ferrari, cuyo trabajo escritural apela regularmente a las categorías de "cuadro" o "dibujo" -aún cuando sea para problematizarlas, como en Cuadro escrito- y se integra más claramente en el circuito artístico contemporáneo, participando activamente en el mismo como una de sus figuras más destacadas (Canclini 2010: 170-176). Es decir, mientras que en el caso de Ferrari estamos ante un "artista que escribe" -alguien que experimenta con la escritura desde el campo del arte- el caso de Dermisache propone un figura más enigmática y elusiva: la de una escritora que se limita a dibujar su escritura y nos propone libros o textos ilegibles, libros para ser leídos y utilizados como tales no obstante su ostensible ilegibilidad.

"Que sea un libro importa" (1970: 51), observa Cozarinsky en un temprano reportaje sobre los grafismos de Dermisache. Ahora bien, no cualquier libro, pues lo que de hecho propone Dermisache es un libro imposible -y no sólo por lo ilegible de la escritura en él contenida sino por desbordar cualquier noción de edición en el sentido convencional del término. De ahí los numerosos problemas que tuvo para publicar su primer libro, así como los sucesivos que ideó a lo largo de su carrera, que frecuentemente quedaron inéditos o se publicaron con décadas de retraso -el Libro $n^{\circ} 2$ de 1972, por ejemplo, se publicó por primera vez en 2008. Cozarinsky refiere cómo el primer libro de Dermisache suscitó el interés de Jorge Romero Brest, a la sazón director del Instituto di Tella, quien remitió a la autora a la editorial Paidós, pero el proyecto de publicación encalló por lo excesivo del libro -un libro de quinientas páginas que finalmente hizo imprimir en 1967 la propia autora, viéndose obligada por razones prácticas a dividirlo en dos volúmenes. Un libro de quinientas páginas ilegibles, "inasimilable para las relaciones establecidas entre producción y consumo dentro de la industria editorial" (Cozarinsky 51), pues si por un lado rechaza la categoría de "libro de artista" y el tipo de edición de lujo usualmente asociado a dicha categoría, por otro prescinde del aparato paratextual que hace que un libro sea legible (título, nombre del autor o el editor, prólogo, colofón, números de página, etc.). Es decir, se trata de un libro que no sólo omite las palabras sino cualquier indicación que pudiera situar $u$ orientar en uno $u$ otro sentido la lectura, cuestionando de entrada su secuencialidad (al omitir los números de página) y dejando fundamentalmente en suspenso su intencionalidad (al suprimir el título y evitar inscribir el nombre de un autor o editor que permitirían suponer la intención de comunicar algún tipo de "mensaje").

21 A la ilegibilidad de los libros de Dermisache contribuye también la extraordinaria heterogeneidad de los grafismos que contienen. Como observa Florent Fajole, la escritura en Dermisache deviene "rápidamente extranjera": "l'écriture est autre à elle- 
même, douée d'autreté'. [...] Aucun code ne produit le nivellement ou l'homogénéisation, le point de fixation qui stabilise la lecture" (2019: 83). Si en Libro № 1 (1967) -el primero que realizó- varios grafismos tienden a producir un efecto de escritura al disponerse en forma de renglones, otros se expanden libremente por la página dibujando figuras caprichosas e imprevisibles [figs. 11, 12 y 13]; si por lo general se deja el envés de la hoja en blanco, en un par de ocasiones también éste se llena de grafías, etc. A ello habría que añadir los múltiples efectos cromáticos, tipos de trazo y estilos escriturales que ensaya en cada página, y el hecho de que casi nunca se repite un mismo estilo. Es decir, lo ilegible de estos primeros libros de Dermisache viene dado no sólo por lo indescifrable de los grafismos sino también por el hecho de reunir en un mismo volumen cientos de estilos y "lenguajes" diferentes que sería imposible remitir a una única clave de desciframiento o incluso a la lógica unificadora de una impronta autorial: lo indescifrable no son sólo los grafismos, sino también y sobre todo la lógica de composición del libro que los reúne. En esto los libros de grafismos de Dermisache se diferencian de las series de "dibujos escritos" de Ferrari, donde la transición entre distintos estilos de escritura -y entre el dibujo y la escritura- es más gradual y orgánica, y va más claramente ligada a una impronta autorial. En Ferrari podemos rastrear una lógica de variaciones en el cultivo de la línea pseudoalfabética realizadas en distintos soportes y materiales, unificadas por el estilo del artista así como por el "relato de la obra" que propone en textos ensayísticos como "Prismas y rectángulos" (1979) y en la misma obra, como es el caso de Cuadro escrito y varios de los "manuscritos" - cosa que Dermisache ostensiblemente procura evitar. A través de distintos medios, materiales y formatos, la impronta autorial de Ferrari se refuerza; cultivando siempre un único medio -el libro o la página ilegible como "espacio alternativo" (Schraenen; Moore/Hendricks)-, la de Dermisache tiende a disiparse en un continuo acto de (des)aparición ${ }^{5}$.

Algo parecido ocurre en el Diario $n^{\circ 1}$. Año 1 (1972). En la portada de este diario ilegible el texto se dispone respetando rigurosamente el esquema de la primera plana de un periódico -con su cabecera, titulares, columnas, recuadros e insertos de distinto tamaño-, y todos los titulares parecen estar escritos en el mismo lenguaje imaginario [fig. 15]. Sin embargo, en la segunda página empiezan a producirse una serie de incoherencias que cuestionan la legibilidad no ya del texto -negada de entrada- sino del medio que lo contiene: dos titulares (si es que lo son) aparecen escritos en el mismo lenguaje indescifrable de la portada, pero más de la mitad de la página es ocupada por un texto que parece escrito en otra lengua. Una lengua no emparentada con la primera, que se vale de un sistema escritural enteramente diferente: si aquella recuerda vagamente al sánscrito, esta propone un patrón de manchas geométricas a modo de variaciones de tachaduras (algo así como si tuviéramos un diario escrito a la vez en latín y en árabe o chino, con el agravante de que aquí no está claro si en el segundo caso estaríamos ante otra "lengua" o ante un sofisticado sistema de censura). En una de las columnas del texto cuyo titular está escrito en este "neo-sánscrito" se produce además una extraña distorsión óptica: un trompe l'œil produce la impresión de que el texto se "levanta" de la página como si repentinamente adquiriera volumen [fig. 16]. Es decir, no sólo se subvierte la legibilidad del texto periodístico sino también la visualidad del medio, arruinando la verosimilitud de la representación. Todo ello contribuye a desmentir el efecto de "página de diario" en el mismo gesto con que se lo invoca, de manera que la pregunta no sería ya “qqué lenguaje es?” o “qué quiere decir?” sino más bien “¿qué es esto?”, “qué clase de artefacto?”. 
23 En la última página se lleva al extremo este doble efecto de indescifrable poliglosia e inverosimilización del medio: por un lado, desaparece por completo el primer lenguaje imaginario (el "neo-sánscrito") y se combinan múltiples lenguajes apócrifos (entre ellos, el lenguaje de periódicas tachaduras que encontramos en la segunda y tercera páginas); por otro, en un nuevo efecto de incoherencia medial, las líneas de uno de esos lenguajes imaginarios desbordan su columna invadiendo el texto vecino (escrito en otro lenguaje imaginario), y el titular de una de las "noticias" (escrita en un lenguaje distinto de los dos anteriores) se "desploma", invadiendo el texto de la noticia [fig. 17]. Héctor Libertella describe este imposible diario como "el número cero de lo que pudo haber sido un periódico" (1993: 257): descripción más que oportuna, pues se diría que en esa suerte de "grado cero" de la escritura periodística se renuevan los inverosímiles artefactos textuales ideados por el Recienvenido macedoniano -ese dudoso reportero especializado en géneros impracticables como el "reportaje sin reporteado", el "artículo que no colabora", el "desperezo en blanco"... En cuanto políglota de lo ilegible, Dermisache recuerda el chiste de Macedonio sobre el "saber callar en varias lenguas" (1996: 14) o su autodescripción en el Museo de la Novela como "polígrafo del silencio" (76). En ese sentido, el objetivo de "desaprendizaje del lenguaje" que Dermisache atribuye a su proyecto -"aprender a desaprender lo que se aprendió como lenguaje" (Becerra $2018 \mathrm{Web}$ )- está directamente emparentado con el "escribir mal y pobre" de Macedonio (1987: 54): en ambos casos se trata de liberar la potencia de un no saber $^{6}$-la "potencia de no", diríamos con Agamben (1998: 63)- orientada a abrir la lectura y la escritura a múltiples des-obramientos.

Dermisache concibe así pues sus grafías ilegibles en la forma de un libro utópico -un libro cuyas condiciones de lectura y publicación no se dan en el presente del sistema editorial ligado a la industria cultural y a la institución artístico-literaria. Ese libro imposible podría compararse con los libros ilegibles que abundan en la literatura de Borges -por ejemplo con el "libro de arena" (Di Ció $2017 \mathrm{Web),} \mathrm{o} \mathrm{con} \mathrm{los} \mathrm{inescrutables}$ libros de su relato "La biblioteca de Babel": el libro circular cuyo lomo continuo coincide con las paredes de la biblioteca, de modo que sus páginas "externas" son perfectamente inaccesibles, o el no menos pernicioso volumen formado por "un número infinito de páginas infinitamente delgadas" (1989: 471). Pero el proyecto de Dermisache parece de hecho más afín a otro imaginario de imposibilidad libresca contemporáneo al de Borges: el proyecto macedoniano de "desencuadernamiento" de lo literario (Prieto 2002) y en particular el libro abierto e interminable que propone su Museo de la Novela. Los libros imposibles de Borges son pesadillescos e intratables inhumanos en cuanto vertiginosos trasuntos del infinito de la escritura ${ }^{7}-$; los de Dermisache, por el contrario, son eminentemente manejables e "imposibles" sólo en el sentido de imaginar condiciones de lectura y edición anacrónicas, que no se dan aún (pero podrían darse en el futuro), y de hecho implican un proyecto utópico de transformación del libro y democratización de la escritura. Los libros imposibles de Borges, en tanto que ligados a la intuición de lo infinito, paralizan al producir el sentimiento estético de lo sublime -ese sentimiento que de acuerdo con la clásica definición kantiana experimentamos ante lo grandioso-; los de Dermisache inducen a la acción, nos invitan a intervenir -y en ese sentido su trabajo con lo ilegible, como en Macedonio, está ligado a un proyecto de transformación ético-política pero a la vez, también, estética. 
El trabajo con la escritura en la forma de páginas sueltas o "papeles" de problemática encuadernación, que hace que la publicación se difiera, o bien lleva a imaginar modos de publicación no convencionales, es de hecho uno de los principales rasgos que comparten ambos proyectos. Las páginas sueltas rearmables ad libitum por el lector en los dispositivos editoriales de Dermisache (Di Ció; Fajole), o las que reúne en sus libros de grafismos ilegibles, en gran parte inéditos o autoeditados, evocan el modelo macedoniano de "papeles desperdigados" que se organizan en un peculiar "(des)arreglo" -baste recordar algunos títulos: Papeles de Recienvenido, "Arreglo de papeles que dejó un personaje de novela creado por el arte" (subtítulo de No toda es vigilia la de los ojos abiertos), Papeles de Buenos Aires, etc. No menos evocan los avatares editoriales del propio Museo de la Novela, libro póstumo del que existen múltiples versiones manuscritas que proponen distintos "desarreglos" de sus páginas, ninguno de ellos definitivo, y del que hay al menos dos versiones publicadas que ordenan prólogos y capítulos de maneras sustancialmente diferentes. Es que Macedonio y Dermisache son escritores secretos -menos literatos que "patógrafos" que cultivan una pasión de escritura al margen de sus réditos simbólicos (Libertella 1993: 222)- a la vez que paradójica o utópicamente públicos: ambos son esencialmente escritores de cuadernos o de páginas en distintos estados de "desencuadernación", a la vez que editores utópicos, lo que podemos vincular con la práctica de la edición alternativa en el ámbito de la neovanguardia sesentista y contemporánea -con figuras como Ulises Carrión, Dick Higgins, Guy Schraenen o Florent Fajole. De hecho, la colaboración de Dermisache con los dos últimos en distintos proyectos editoriales es una de las instancias más notables de esa práctica de edición vanguardista (Fajole; Gilbert), y su proyecto de escritura ilegible entraría de lleno en lo que Carrión llamó el "arte nuevo de hacer libros": "In the old art the writer writes texts. / In the new art the writer makes books" (1980: 8). Todo lo cual se anticipa en ese libro utópico que es el Museo de la Novela, tan secreto como inusitadamente "publicado" como acción de arte colectiva en el marco de una humorística campaña presidencial (Prieto 2010: 61-85), en lo que vendría a ser un raro y temprano caso de "edición alternativa".

“Todo su trabajo está en diferir, o toda su diferencia es un trabajo" (1993: 258), observa Libertella sobre los grafismos de Dermisache, vinculándolos con la noción de "trabajo humano lingüístico" del semiólogo Ferruccio Rossi Landi:

Es en este sentido que puede comenzarse a hablar de trabajo humano lingüístico. La expresión tiene el valor de poner este tipo de trabajo al mismo nivel del trabajo "manipulativo" o "transformativo" con el que se producen objetos físicos. De tal manera, el trabajo lingüístico y el no lingüístico, como especies arbitrariamente separadas en general, son llevados nuevamente a la clase a la que pertenecen con iguales derechos. (Rossi Landi 12-13)

La escritura ilegible de Dermisache, vale decir, es un trabajo que activa la dimensión manipulativa y transformativa del lenguaje, y que se orienta a la producción de un objeto material: un libro de grafismos. En cuanto trabajo humano lingüístico, es un trabajo feliz, que Libertella relaciona inmediatamente con la noción de utopía -utopía de la liberación de la tiranía del significado, del agotamiento del "sano sentido": "Es la sensación de felicidad que deja, también, este tipo de trabajo: la del agotamiento; no hay lugar para que el sano sentido descanse -la utopía agota" (1993: 258). Ya lo decía Macedonio: "Lectura de trabajo: leerás más como un lento venir viniendo que como una llegada" (1987: 133). Ese trabajo utópico, "contra-natural" en cuanto "lectura-escritura a venir" tanto en Macedonio como en Dermisache -trabajo "contra la naturaleza del 
periódico, del libro, de las bibliotecas" (Libertella 1993: 262)-, se orienta en primer lugar a la transformación del lector, a un cambio radical del papel que se le asigna en lo que con Macedonio llamaríamos la "asendereada-estructura-tradicional-delencuadernamiento-de-lo-literario" (1996: 124). El lector, observa Libertella a propósito de Dermisache, deviene "objeto de una estrategia secreta de desplazamiento propiciada desde el producto mismo" (1993: 262), con lo que se tiende a abandonar lo que Rossi Landi llama la función "repetidora" del "obrero lingüístico" (55), a la vez que se libera su función creadora.

La propuesta de una ilegibilidad que activa la libertad creadora del lector -una ilegibilidad no sublime, que incita a la acción transformadora en el plano del "trabajo humano lingüístico"- es tan central en Dermisache como en Macedonio. "Lo dejo libro abierto", dice éste en el "prólogo final" del Museo de la Novela (1996: 253), invitando a lectores futuros a continuar un texto por definición inconcluible; y Dermisache, acerca de su trabajo: "Yo decía: es la lectura a partir de quien lo toma" (Rimmaudo/Lamoni 2011 Web). Y si Macedonio imaginará una utópica "colectivización" del trabajo literario, proponiendo una suerte de cooperativa autorial transhistórica que trabajaría sobre los mismos textos a lo largo del tiempo (1944: 4) -dando en cierto modo el primer paso en el Museo de la Novela-, Dermisache incorpora la participación activa del lector tanto en su filosofía de la composición del libro "manejable" como, de manera muy concreta, en los dispositivos editoriales que realiza en los 2000. En ellos invita a cada cual a armar su propio libro y llevárselo a casa, a partir de una serie de páginas sueltas con reproducciones de grafismos, así como invita a rellenar los recuadros en blanco que deja en sus Historietas (ca. 1970) o en la tira cómica incluida en Diario № 1. Año 1 [fig. 18], o como promueve los "trabajos por sumatoria" en su Taller de Acciones Creativas (Cañada 2015; 2019), y especialmente en las seis Jornadas del Color y de la Forma (organizadas entre 1975 y 1981) en las que "el público accedía a una misma superficie de trabajo y trabajaban simultáneamente sumando a lo ya hecho, lo nuevo" (Rimmaudo/Lamoni $2011 \mathrm{Web).}$

29 En estas propuestas, y en general en la idea de un libro ilegible y manejable que se invita a manipular y rearmar a voluntad, se trataría entonces de liberar al lectoespectador de ese específico modo de alienación ligado a la tiranía del sentido preestablecido: tiranía de la intentio auctoris así como de los esquemas de significación que imponen determinados formatos escriturales -lo que Barthes llama "formas contingentes de la expresión" (2006: 11): libro, carta, diario, historieta, etc.-, o los que dictan determinados espacios institucionales: museo, galería, feria de arte, etc. Es decir, se trataría de liberar la potencia productiva del lector en cuanto creador de sentido proyecto en el que la "muerte del autor" barthesiana se alía con una idea que recorre los discursos utópicos modernos en sus varias vertientes políticas, filosóficas y artísticas desde Marx a Joseph Beuys y Henri Lefebvre: la idea de que todo ser humano es un creador y de que la vida cotidiana debe aspirar a la condición del arte.

\section{Cómo hacer cosas lingüísticas sin palabras (a modo de conclusión)}

El poeta Arturo Carrera aprecia una cualidad zen en los grafismos de Dermisache (1981: 33). Es algo que podemos vincular con el abandono del yo "expresivo" como fundamento del sentido y el valor de la obra de arte -algo que comparten los grafismos 
de Dermisache y la obra pseudoalfabética de Ferrari-, así como con la disipación de la autoría a la que, como hemos visto, tiende más bien aquella que este. La operación de vaciamiento del yo que reconoce Carrera tendría algo que ver con la "metafísica sin sujeto" del budismo zen que para Barthes está en la base del haikú (1981: 18). En su lúcido ensayo sobre esa forma poética el crítico francés hace algunas observaciones especialmente relevantes para la discusión sobre lo ilegible. Observa Barthes que, a la "desmesura" de la demanda de sentido del lenguaje, el haikú opone un ejercicio de mesura -una neutralización o "exención" del sentido "a través de un discurso perfectamente legible" (19). Se trata, afirma, de un ejercicio en el que "la seguridad y la independencia del gesto no remiten ya más a una afirmación del yo (a una 'suficiencia') sino solamente a un modo gráfico de existir" (19), un ejercicio que describe en términos plásticos, extrapolándolo a los modos de conducta cotidiana, a la gestualidad que lee al deambular por una calle japonesa:

esta escritura alla prima en la que el esbozo y el arrepentimiento, la maniobra y la corrección son igualmente imposibles, porque el trazo, liberado de la imagen ventajosa que el escribiente querría dar de sí mismo, no expresa sino hace existir simplemente. Cuando camines, dice un maestro Zen, conténtate con caminar. Cuando estés sentado, conténtate con estar sentado. Pero, sobre todo, jno vaciles! (19)

31 En su trabajo con la línea pseudoalfabética, Dermisache y Ferrari dan un paso más allá en la liberación del trazo: operan una "exención del sentido" por medio de una escritura perfectamente ilegible - perfecta en el sentido de que en ella no hay posibilidad alguna de desciframiento-, y así diríamos que cultivan una mesura de la grafía que es también una mesura del yo: un cuestionamiento de la "suficiencia" del sujeto que sostiene la autoría literaria y artística -algo que se esboza decididamente en ciertos momentos de la obra de Ferrari ${ }^{8}$, y que adquiere carácter programático en la de Dermisache, la cual en gran medida es continuadora del "almismo ayoico" macedoniano y sus notorias prácticas "egocidas" (Vecchio 2003).

Cuando Barthes afirma que los grafismos de ésta captan la "esencia" de la escritura, aventuraríamos que se refiere sobre todo a esto ${ }^{9}$. Se trata de una cuestión relacionada con un motivo que recorre su ensayo Variations sur l'écriture (1974) y que es tan relevante para los grafismos de Dermisache como para la obra "no significativa" de Ferrari: la diferencia entre la escritura y el lenguaje oral, es decir, la diferencia de la escritura en cuanto acción que concierne a la mano y que implica una intervención del cuerpo distinta a la que conlleva la comunicación oral, ligada a la boca y al "aparato de fonación facial" (2006: 68). Según esto, la escritura permite una suspensión del yo que no es posible en el lenguaje oral (o en el lenguaje reducido a la función comunicativa). Una mano, desde esta perspectiva, viene a ser como cualquier otra mano; en cambio la boca pone en juego el rostro y por lo tanto el sujeto - mi rostro en tanto que distinto de cualquier otro, i.e., en tanto que continuamente interpelado y confrontado por otro(s), lo que necesariamente implica el posicionamiento de un yo frente a un tú, frente a otro(s). La escritura permite así el desposicionamiento de la enunciación, y de ese modo hace posible el olvido o la suspensión del yo -un lujo que no suele estarle permitido al lenguaje oral (o al lenguaje en su dimensión comunicativa). En ese sentido, todo "yo" escrito sería por definición "autoficcional", en tanto que enunciación des-posicionada, exenta del vínculo con un tú (un otro) presente. El yo sólo es real cuando habla a un tú -a otro(s)-: es el tú, el otro que escucha, quien otorga existencia al yo al recibir su mensaje. De ahí lo crucial del "entender" en el lenguaje oral (en el lenguaje en cuanto comunicación): todo un sistema de realidad depende de ello, pues "entender un 
mensaje" implica ante todo otorgarle realidad a quien lo emite, reconocer como real un mundo momentáneamente compartido. La "realidad" del mundo de los hablantes es esencialmente performativa: es un efecto que se (re)produce por multiplicación de actos comunicativos en que un emisor y un receptor se otorgan mutuamente realidad y se reconocen como sujetos dentro de un mismo mundo al entender cada uno el mensaje del otro. Nada de esto atañe a la escritura, que como observa Barthes es ajena a la función comunicativa inherente al lenguaje oral -y por ende al reconocimiento de la realidad de un mundo que está en juego en el "entender". La escritura sería, antes bien, el ámbito por excelencia del "no entender" y del "no reconocimiento", ámbito de liberación de la tiranía del sentido y de la demanda de realidad -ámbito por tanto propicio a la imaginación de mundos alternativos, a la construcción de hipótesis y utopías, a la invención de lenguajes.

Que la escritura -y en particular lo que llamaríamos escritura poética: aquélla que pone en juego la escritura en su "verdad", no en su "instrumentalidad" (Barthes 1982: 143)sea el ámbito privilegiado de la suspensión del yo y la exención del sentido -el ámbito por excelencia de la puesta en suspenso del entender y del reconocimiento- no la inhabilitaría para la intervención política ni la convertiría en algo ajeno al "diálogo social" -por el contrario, ella es el ámbito donde se da propiamente ese diálogo. Pues cualquier proposición que aspire a interpelar a la sociedad en su conjunto -i.e., a la totalidad de un conjunto de individuos y relaciones- requiere por definición la no presencia de dicha totalidad en su acto enunciativo (Andrews 1996: 81). Es decir, cualquier forma de "diálogo social" requiere un acto de suspensión o puesta en ausencia de los mecanismos de reconocimiento que (re)producen la "realidad social": esto es lo que hace posible en primer lugar interpelarla y pensarla más allá de poder "hablar" en ella o sobre ella, y más allá de los sistemas de sentido que regulan ese hablar. Tal la prerrogativa y la promesa de la escritura: la promesa de (no) sentido y de traslado subjetivo que sería el fundamento de su dimensión ética y política. No otra cosa está en juego en la escritura cuando se moviliza en su esencia, en su "potencia de no". Y es precisamente este tipo de intervención, quisiera sugerir, el que operan las escrituras ilegibles de Dermisache y Ferrari -una intervención de naturaleza esencialmente política, justamente por poner en juego la escritura en su (im)potencia.

Al confrontarnos con una escritura que "no dice nada", los grafismos pseudoalfabéticos de Dermisache y Ferrari relegan a un segundo plano el "entender" en la misma medida en que nos convocan a un "hacer". De ese modo realizan una operación intrínsecamente política -no en el sentido de la consigna o la denuncia puntual o del compromiso con una determinada ideología, sino en el más básico de lo que con Rancière llamaríamos una "redistribución de lo sensible" (2004: 38). Es decir, lo político no atañe aquí a un posicionamiento ante un hecho concreto o un determinado campo de lucha ideológica, sino que más bien tiene que ver con un fundamental reposicionamiento de la lectura y con una no menos decisiva transformación de la escritura no es un hecho discursivo, algo que sucede en la superficie del lenguaje (un "mensaje"), sino un acontecimiento en su estructura profunda, una intervención en las condiciones de posibilidad del lenguaje y los discursos. Lo intrínsecamente político de estos proyectos no se daría, así pues, en las instancias de reacción ante un evento o situación política concreta, en las que se esboza un "mensaje" o un gesto de denuncia; es decir, en lo que tanto Dermisache como Ferrari consideran lo más "político" de sus respectivas obras: en los grafismos que desbordan la columna asignada en el Diario №1 (1972) de Dermisache para aludir a la matanza de Trelew (Rimmaudo/Lamoni 2011 Web; Bruno 
$2018 \mathrm{Web})$, o en lo que Ferrari llama su obra "significativa": las acciones de protesta en que se involucra entre 1965 y 1975, o los collages más o menos escandalosos que realiza a partir de La civilización occidental y cristiana. Por el contrario, lo esencialmente político de estas prácticas emerge en sus momentos de mayor ilegibilidad, cuando no se trata de la política a través de, o de la política en, sino cuando lo que está en juego es, de la manera más básica, la política de la escritura (Rasula 1987: 317; Dworkin 2003: 4-5) ${ }^{10}$. Con distintos acentos, estas escrituras ilegibles nos interpelan estética y políticamente en su "potencia de no": en los momentos que omiten todo asidero que permitiría encauzar el sentido, y en vez de transmitir un posicionamiento ideológico nos exponen a un radical des-posicionamiento y a un vaciamiento del discurso: a una fundamental desorientación del lenguaje en el (no) sentido de la escritura.

Como dirían Deleuze y Guattari: "nada de problema de sentido, sino tan sólo de uso. Nada de originario ni de derivado, sino una derivación generalizada" (1973: 38). En el trabajo del grafismo pseudoalfabético como liberación del sentido o "deriva generalizada" orientada a producir un "objeto útil" o a multiplicar los des-obramientos habría que destacar, en Dermisache, la refuncionalización del libro, que de repositorio de significados ligados a una hermeneútica del sujeto es devuelto a la inmanencia del "objeto útil", y en Ferrari, el desmontaje del libro movido por una notoria vocación biblioclasta -así como, en la medida en que es algo que no sólo concierne a su obra "significativa", el desmontaje del Libro por antonomasia en la tradición occidental (la Biblia): una operación carnavalesca por la que se ilegibilizan las escrituras (sagradas o canónicas, en el amplio sentido del término). Pero sobre todo habría que destacar, en ambos, el hecho de que el trabajo con lo ilegible es un trabajo lingüístico. Pues, para ponerlo en términos de un clásico de la lingüística estrictamente contemporáneo a estas propuestas -How to do things with words (1962)-, en las escrituras ilegibles y en los lenguajes imaginarios de Dermisache y Ferrari -y esto podría servir como conclusión convenientemente abierta- la cuestión fue siempre en cierto modo y sigue siendo: cómo hacer cosas lingüísticas sin palabras. 


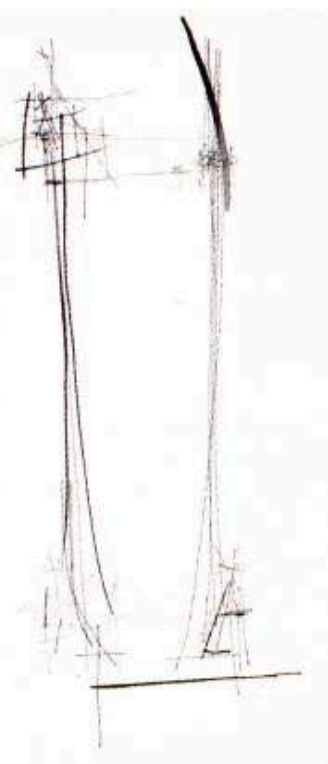

nitu

Sin titulo, 11/3/1962. Tinta china sobre papel, $34 \times 24 \mathrm{~cm}$. Col. Alicia y León Ferrari.

Fig. 1. León Ferrari, Sin título (1962).

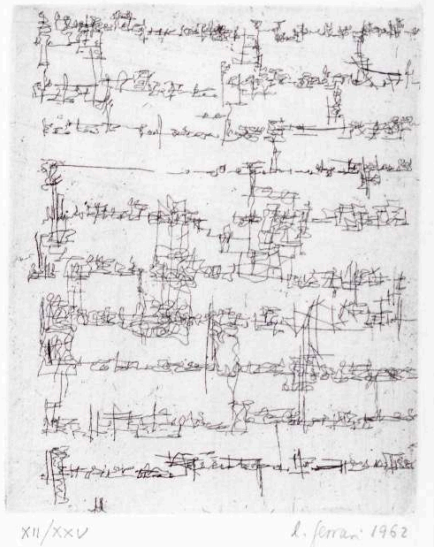

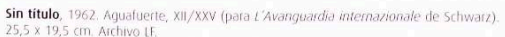

Fig. 2. León Ferrari, Sin título (1962). 


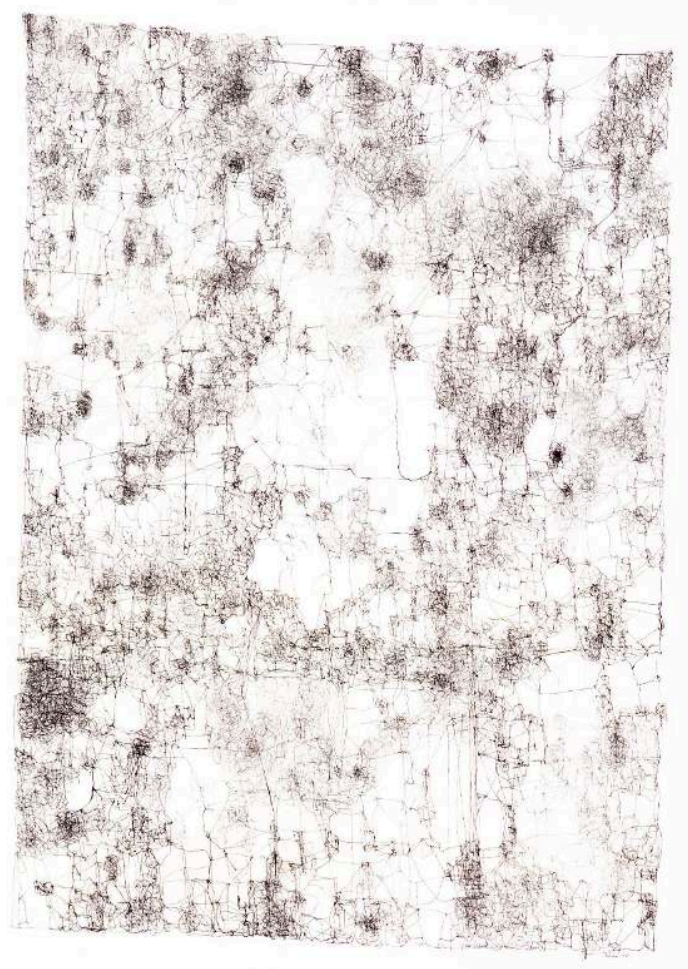

Fig. 3. León Ferrari, Sin título (1962).

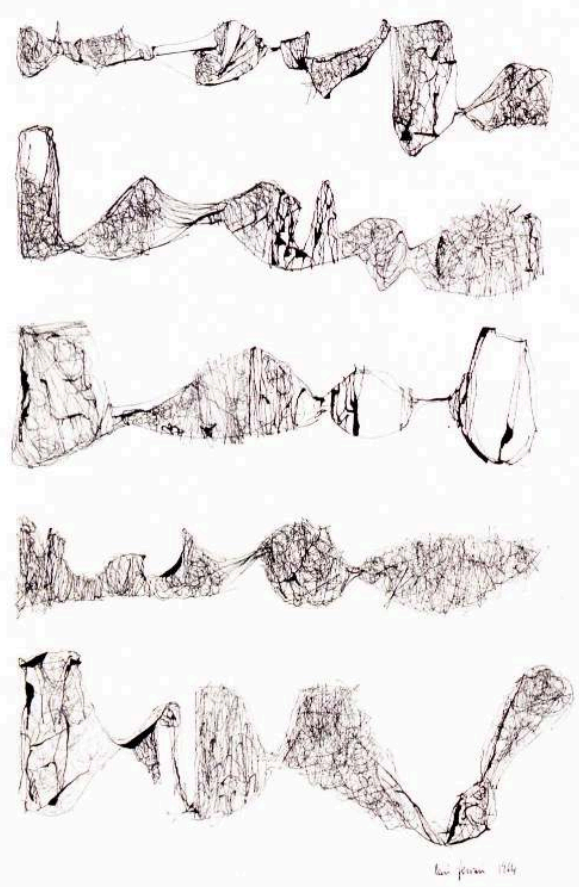

Fig. 4. León Ferrari, Sin título (1962). 


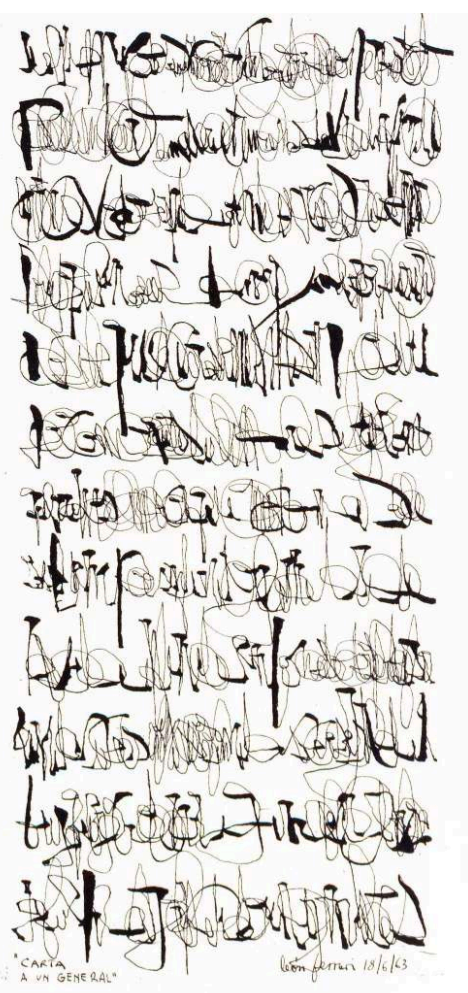

Fig. 5. León Ferrari, Carta a un general (1962)

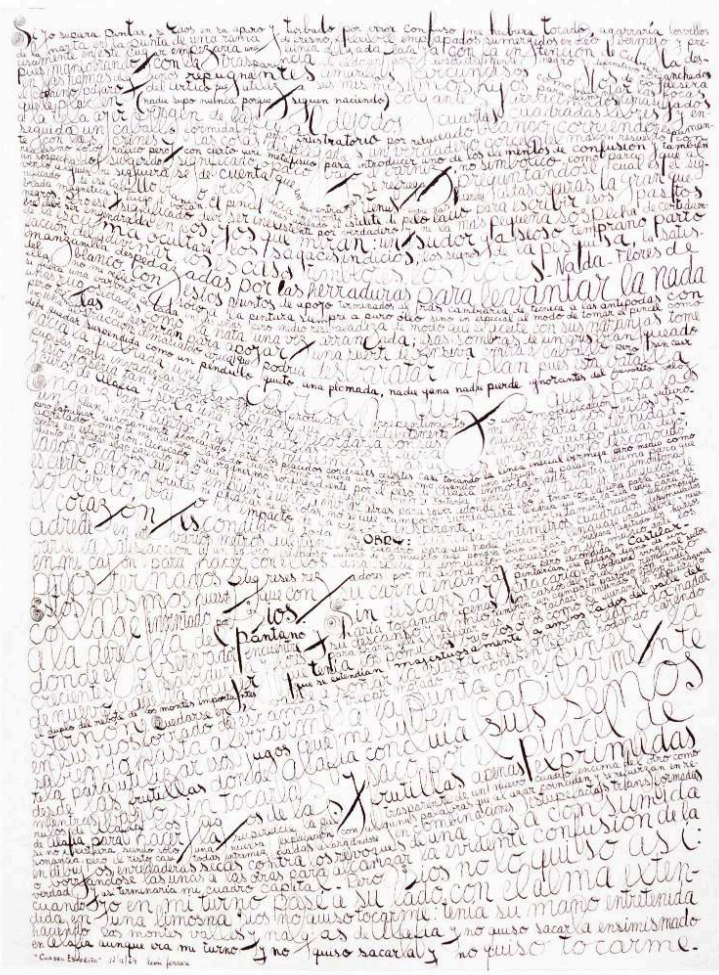

Fig. 6. León Ferrari, Cuadro escrito (1964) 


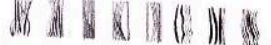

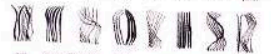
1.NO IVIM

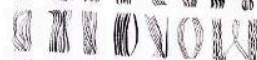

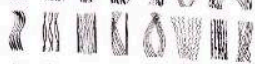

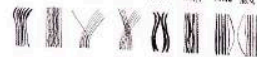

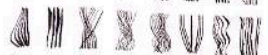
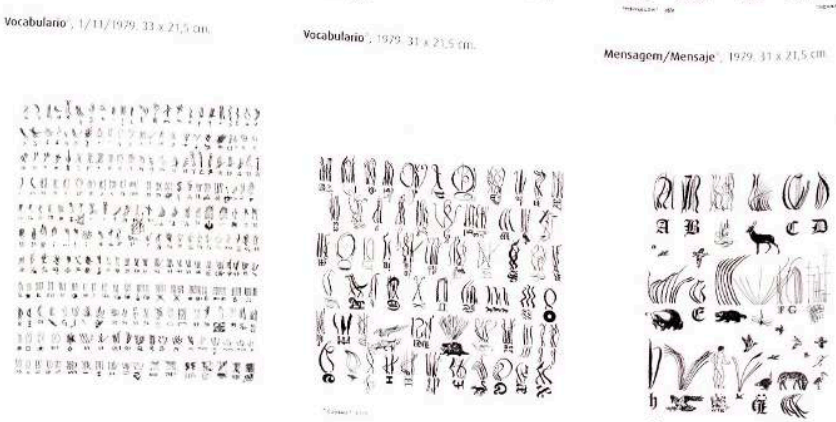

Fig. 7. León Ferrari, Códigos y vocabularios (1979).
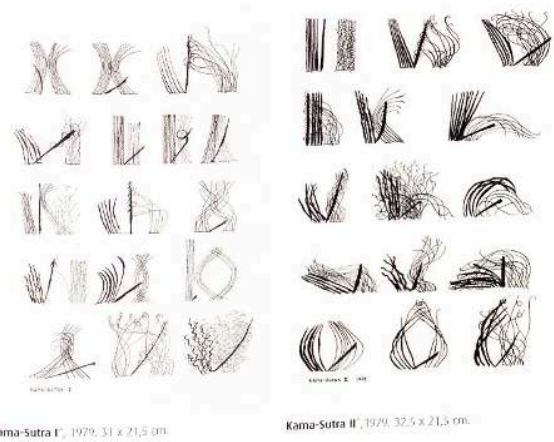

(1) NIII

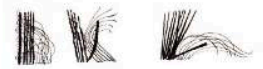

Whar (D)

(1)

KIXIN

$\ldots 1$

(3)

(II) 1

* I $/$ of

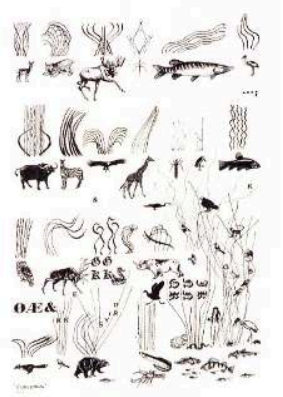

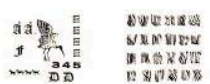

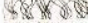

(ars) $x+2$

sorox

(4)

Ning 80

mysy.y.

28

(8)

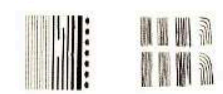

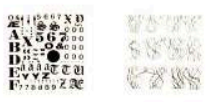

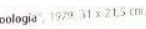

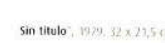

Fig. 8. León Ferrari, Kamasutras y traducciones (1979). 


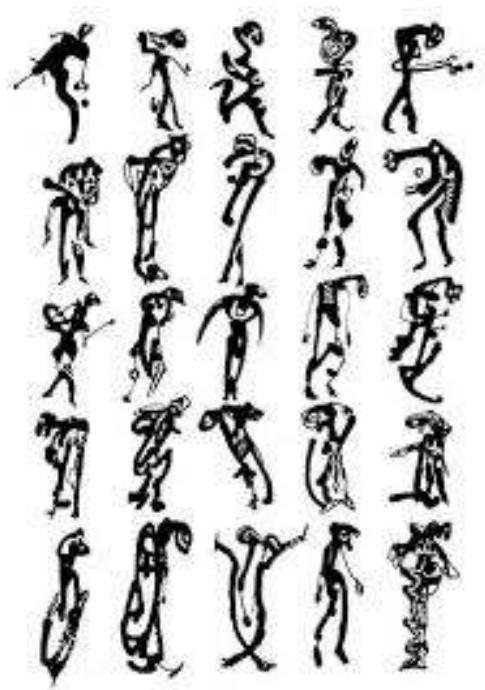

Fig. 9. José-Miguel Ullán, Ni mú (2002).

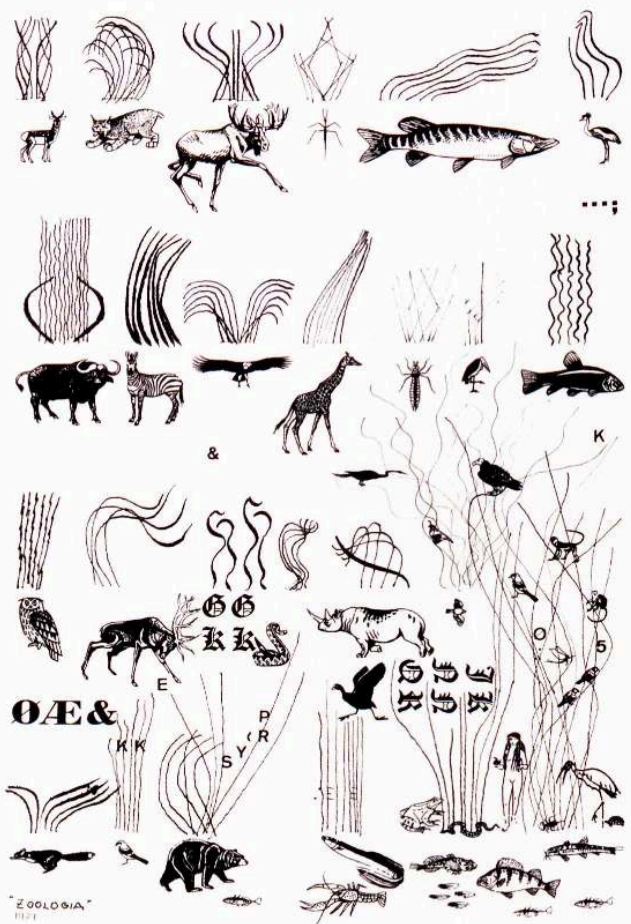

Fig. 10. León Ferrari, Zoología (1979). 


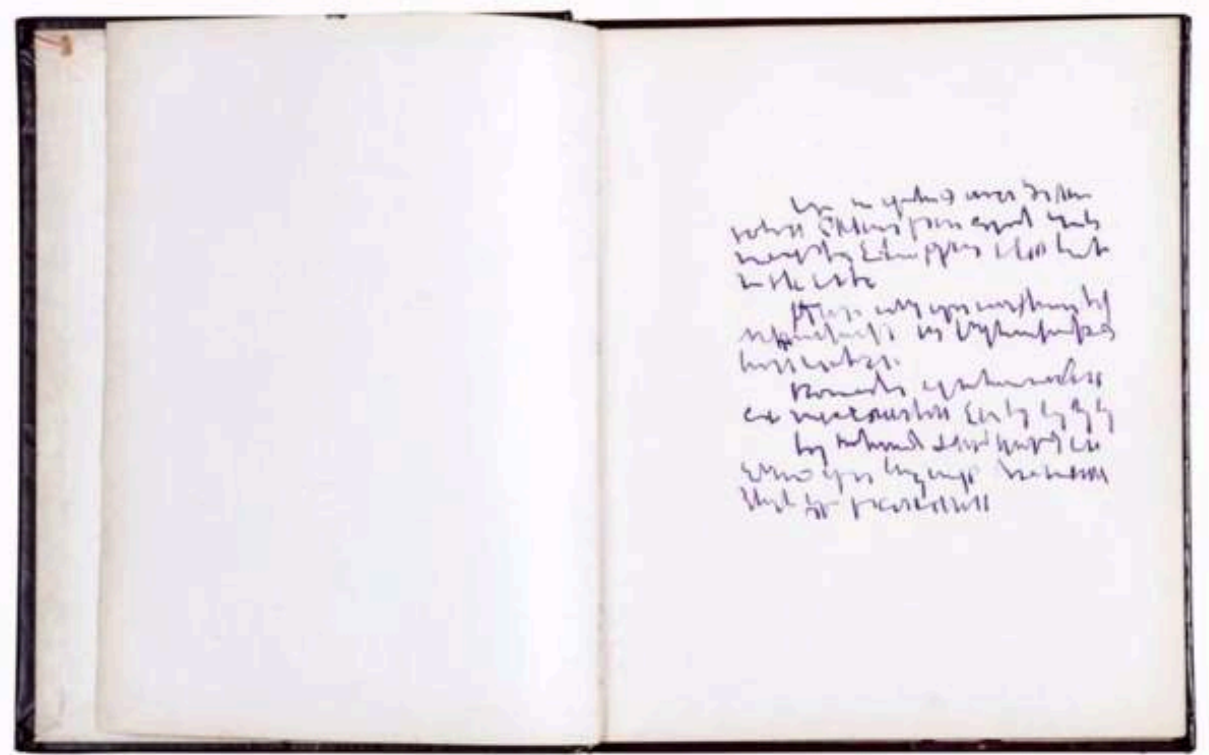

Fig. 11. Mirtha Dermisache, Libro No 7 (1967).

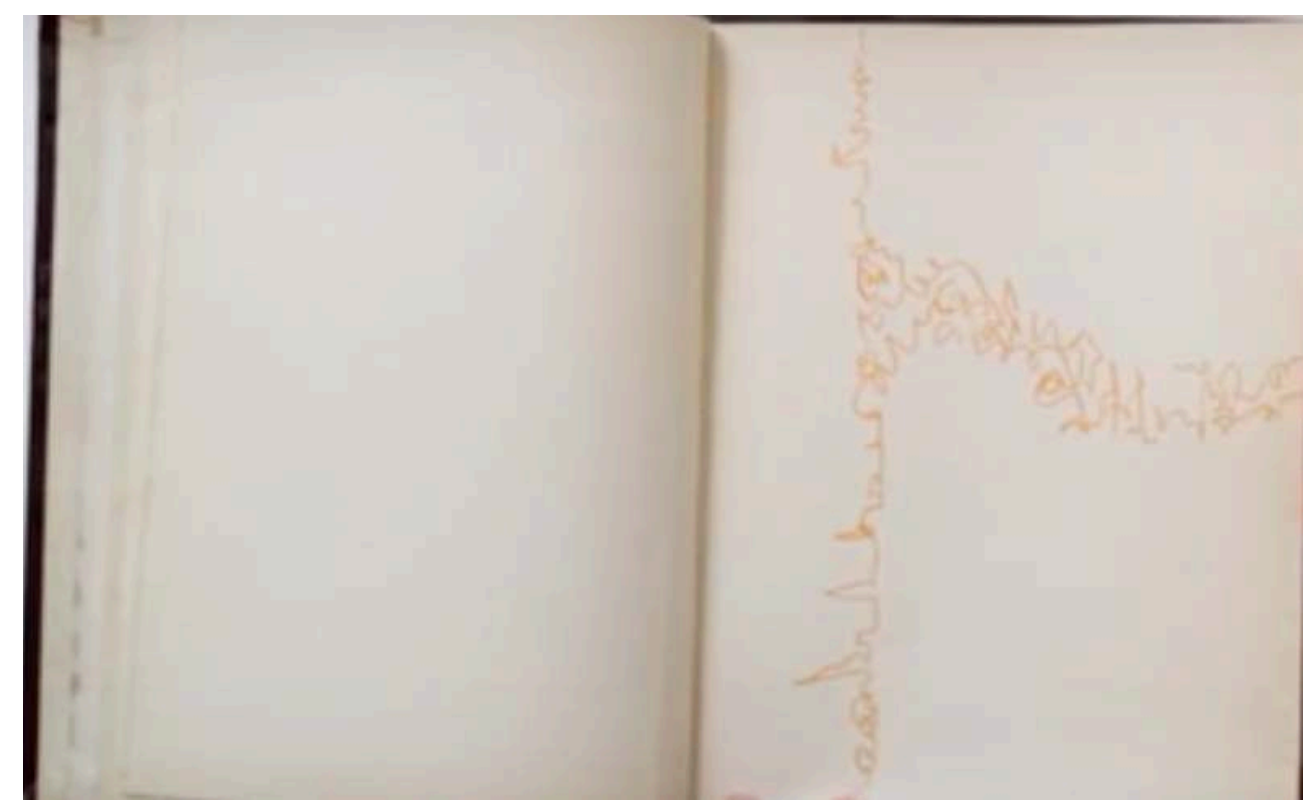

Fig. 12. Mirtha Dermisache, Libro No 7 (1967). 


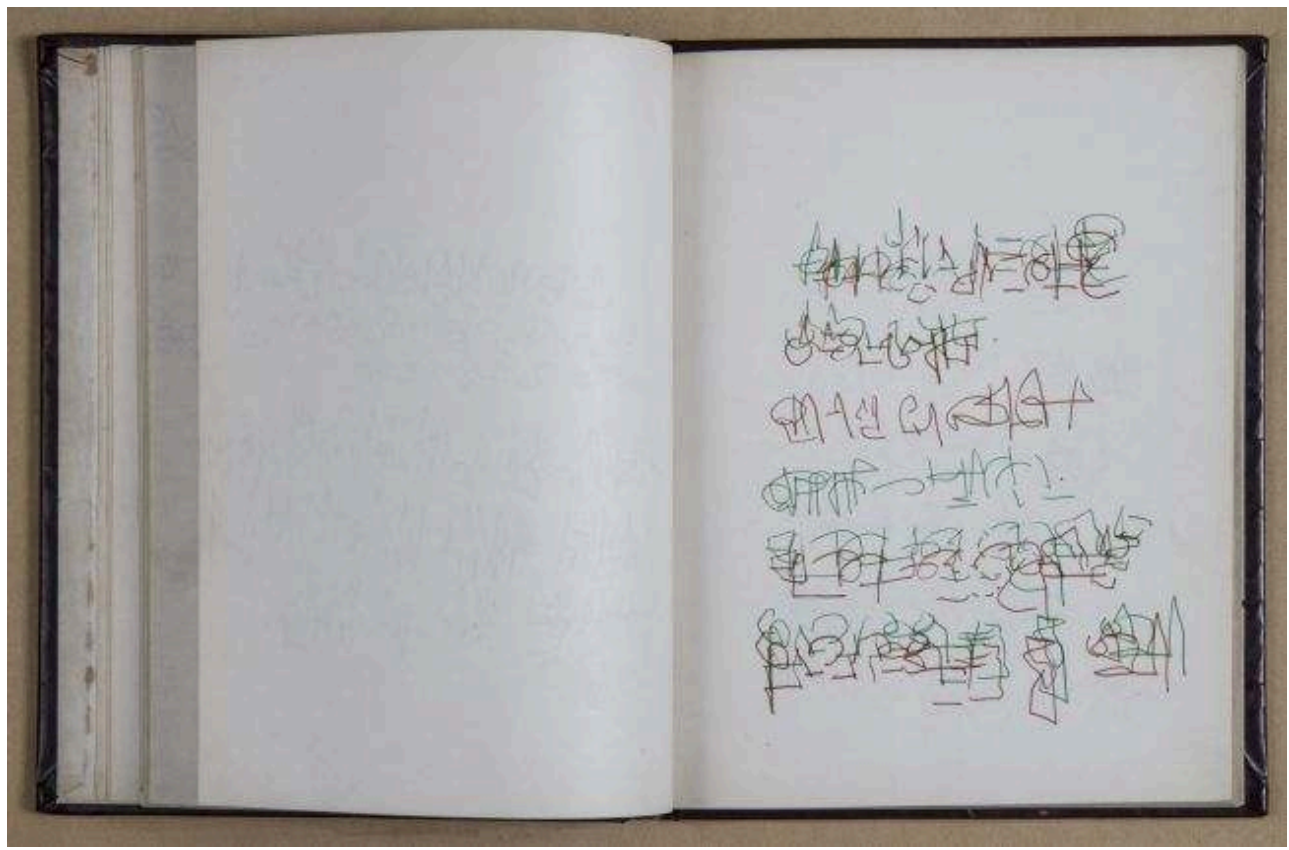

Fig. 13. Mirtha Dermisache, Libro No 7 (1967).

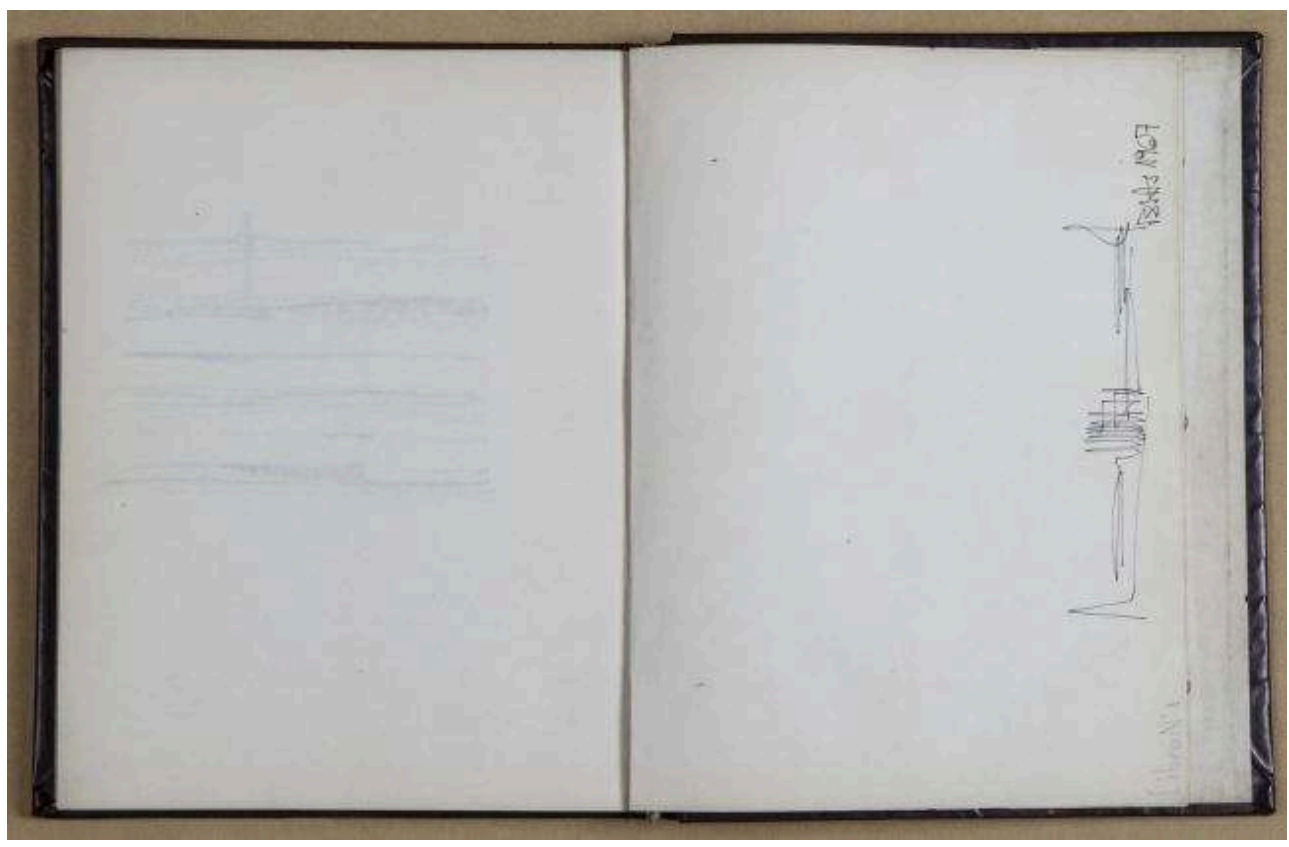

Fig. 14. Mirtha Dermisache, Libro No 1 (1967) [última página]. 


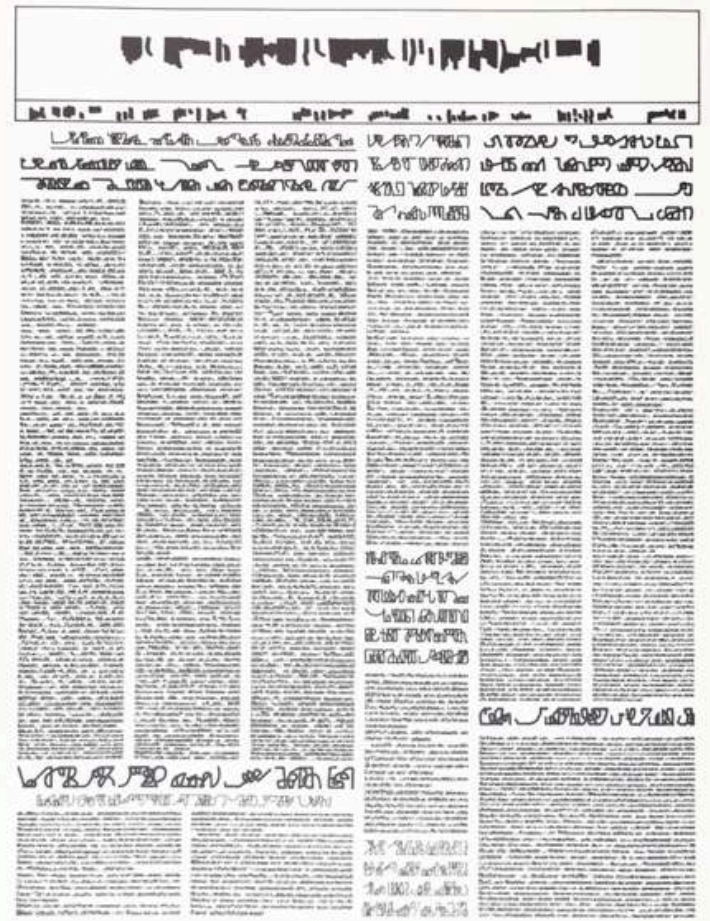

Fig. 15. Mirtha Dermisache, Diario No 1 . Año 7 [portada] (1972).
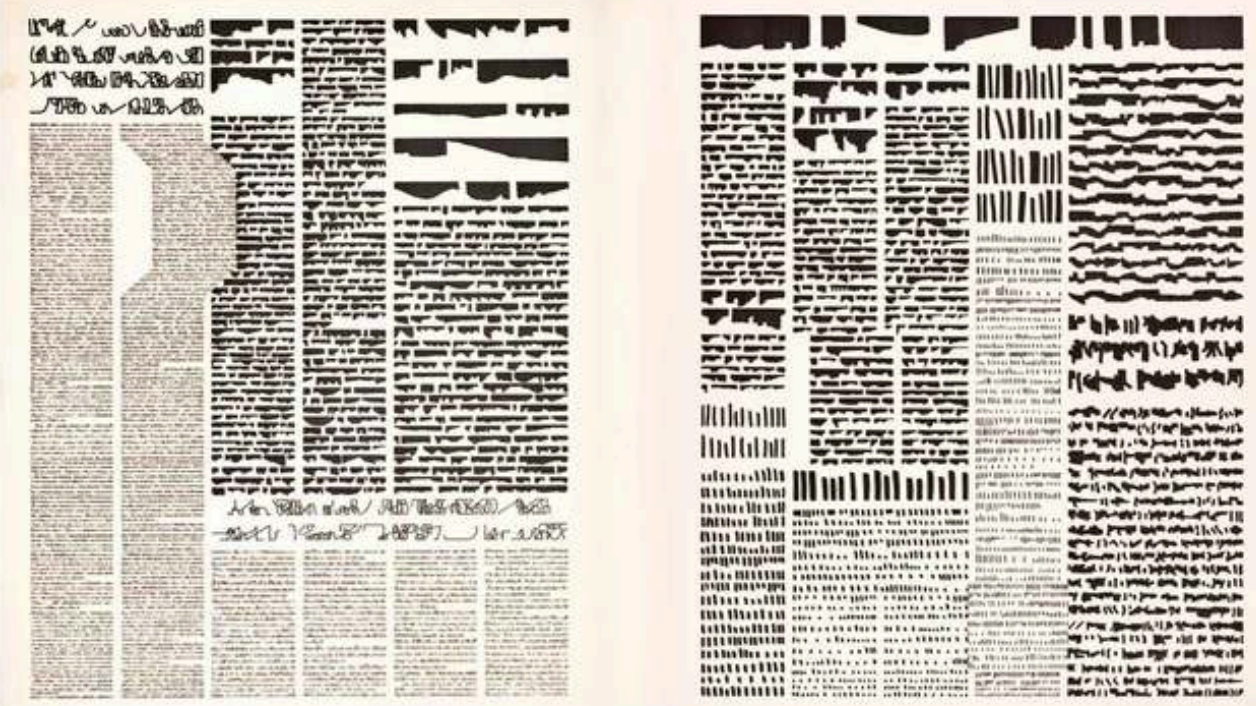

Fig. 16. Mirtha Dermisache, Diario No 1. Año 7 [interior] (1972). 


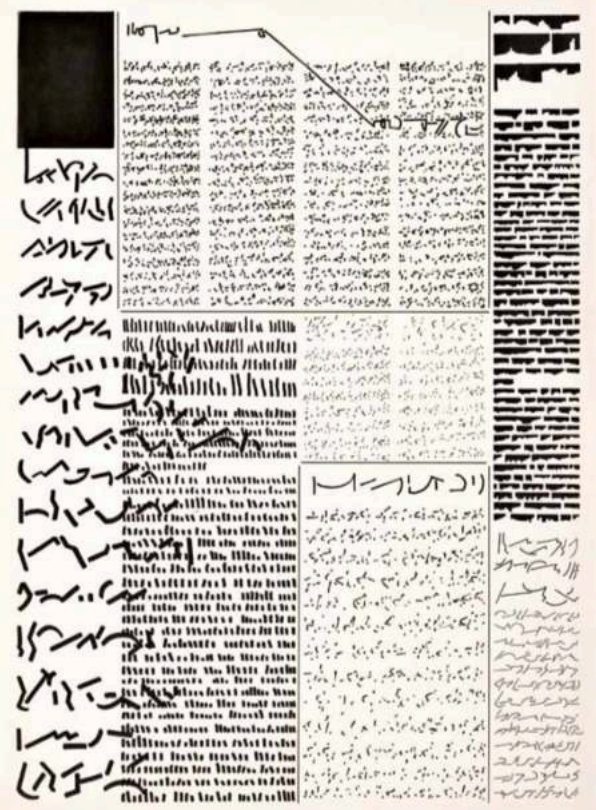

Fig. 17. Mirtha Dermisache, Diario No 1. Año 7 [interior] (1972).

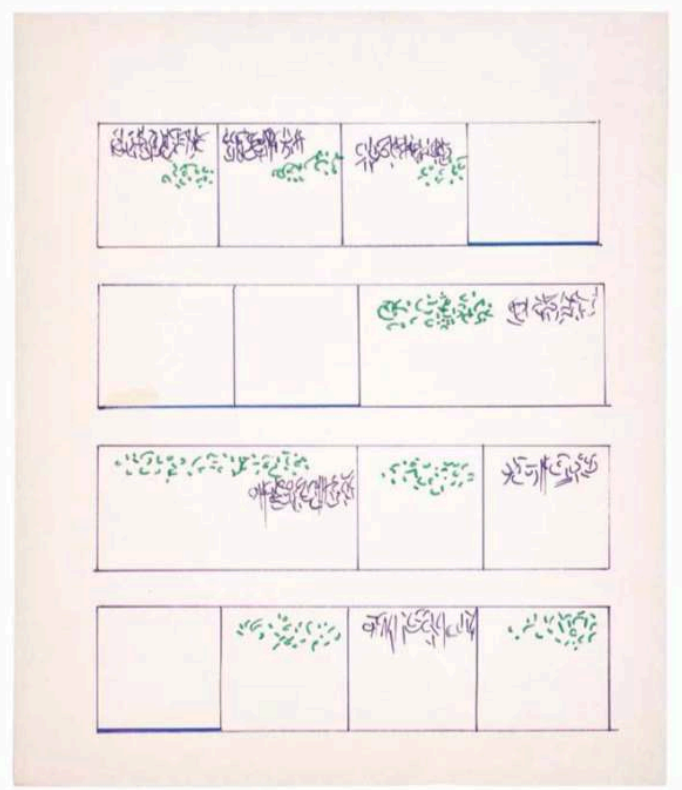

Fig. 18. Mirtha Dermisache, Sin título (Historieta), ca. 1972-1974. 


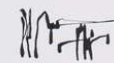

苻梮

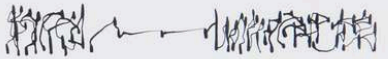

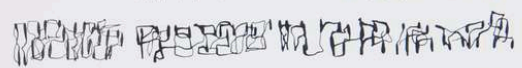

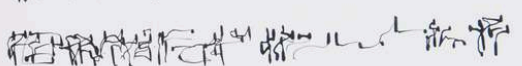

Hir

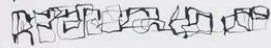

$\forall F+r i d$

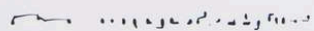

sis

36

Fig. 19. Mirtha Dermisache, Sin título (carta), ca. década 1970.

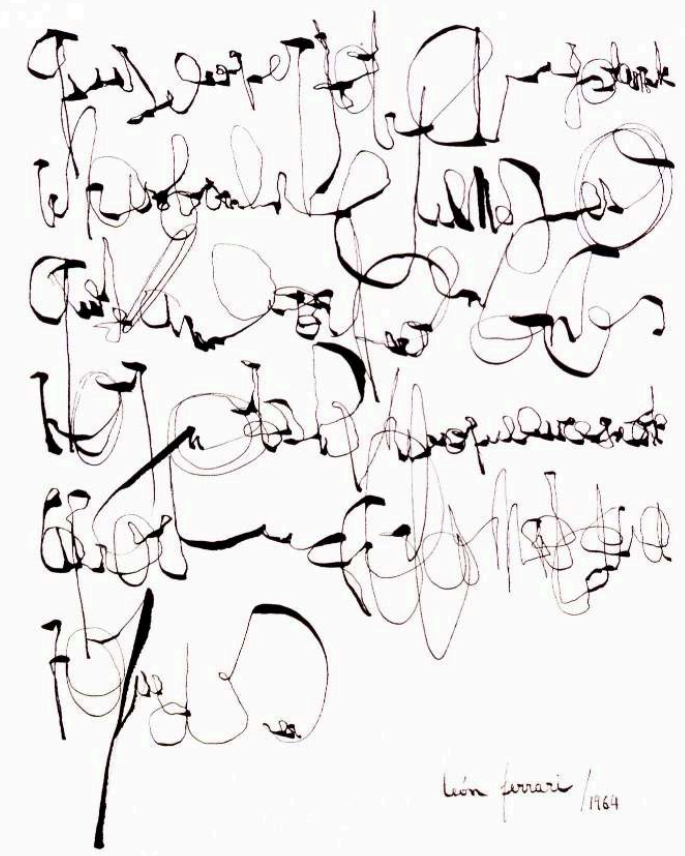

Fig. 20. León Ferrari, Sin título (1964). 


\section{BIBLIOGRAPHY}

Agamben, Giorgio, Homo sacer. El poder soberano y la nuda vida, Valencia, Pre-Textos, 1998.

Traducción de Antonio Gimeno Cuspimena.

Andrews, Bruce, Paradise and Method: Poetics and Praxis, Evanston, Northwestern University Press, 1996.

Austin, John L., How to do things with words, Oxford, Clarendon Press, 1962.

Barthes, Roland, “Accordons La liberté de tracer”, L'orthographe, Le Monde de l'Éducation n¹3, janvier 1976, p. 7.

---, Variations sur l'écriture, Mainz, Dieterich'sche Verlagsbuchhandlung, 2006 [1974].

---, “El haiku”, Xul. Signo viejo y nuevo. Revista de poesía no 3, diciembre 1981, p. 15-20. Traducción de Javier Sicilia y Jaime Moreno Villarreal.

---, "Fragment d'une lettre de Roland Barthes adressée à Mirtha Dermisache,

le 28 mars 1971", Cahier du Refuge nº 130, 2004, Marseille, Centre International de

Poésie.

---, “Sémiographie d'André Masson", L'Obvie et l'obtuse, París, Seuil, 1982.

Baxandall, Michael, Giotto and the Orators: Humanist Observers of Painting in Italy and the Discovery of Pictorial Composition, 1350-1450, Oxford, Clarendon Press, 1971.

Benveniste, Émile, “L’Appareil formel de l'énonciation”, Problèmes de linguistique général, vol. 2, París, Gallimard, 1974.

Becerra, Felipe, "Mirtha Dermisache: desaprender a escribir", 21 de junio de 2018, Blog, Web. Consultado el 10/03/2020.

Biscia, Rodolfo, "Esculturas y dibujos musicales de León Ferrari, en un museo junto al mar", Infobae, 26 de febrero de 2020, Web. Consultado el 26/02/2020.

Blumenberg, Hans, La legibilidad del mundo, Paidós Ibérica, 2000 [1981]. Traducción de Pedro Madrigal Devesa.

Borges, Jorge Luis, “El idioma analítico de John Wilkins”, Obras completas, vol. 2, Buenos Aires, Emecé, 1989, p. 84-87.

---, “Del rigor en la ciencia", Obras completas, vol. 2, Buenos Aires, Emecé, 1989, p. 225.

---, “El Golem”, Obras completas, vol. 2, Buenos Aires, Emecé, 1989, p. 263-265.

---, “La biblioteca de Babel”, Obras completas, vol. 1. Buenos Aires, Emecé, 1989, p. 465-471.

Bruno, Fernando, "Sobre el lenguaje y sus límites: las escrituras ilegibles de Mirtha Dermisache", 14 de noviembre de 2018, Blog, Web. Consultado el 10/03/2020.

Cañada, Lucía, “Apuntes sobre arte y educación. Una mirada sobre las experiencias pedagógicas impulsadas por Mirtha Dermisache: el taller de Acciones Creativas y las Jornadas del Color y de la Forma", Educación, lenguaje y sociedad, vol. XVII, nํ17, noviembre 2019, p. 1-32.

---, “¿Libre expresión gráfica en dictadura? Las Jornadas del Color y de la Forma”, Questión, vol. 1, nº 45, enero-marzo de 2015, p. 69-77. 
Carrera, Arturo, “Tejidos esponjosos”, Xul. Signo viejo y nuevo. Revista de poesía n⿳ํㅡㄹ diciembre 1981, Buenos Aires, p. 29-33.

Carrión, Ulises, “The New Art of Making Books”, Second Thoughts, Amsterdam, VOID Distributors, 1980, p. 5-22.

Castro Godoy, Jimena, “Leer lo ilegible: los casos de Mirtha Dermisache y León Ferrari”, Actas del congreso internacional de "poesía hispanoamericana: de la vanguardia a la posmodernidad", Gladys Flores Heredia et al. (ed.), Lima, Academia Peruana de la Lengua, 2012, p. 335-356.

Cozarinsky, Edgardo, "Un grado cero de la escritura", Panorama, año VII, n 156, 21 de abril de 1970, p. 51.

Davis, Fernando, "Poéticas oblicuas", Poéticas oblicuas: modos de contraescritura y torsiones fonéticas en la poesía experimental (1956-2016), Buenos Aires, Fundación OSDE, 2016, p. 9-45.

Deleuze, Gilles y Félix Guattari, El antiedipo: capitalismo y esquizofrenia, Barcelona, Barral Editores, 1973. Traducción de Francisco Monge.

Dermisache, Mirtha, Publicaciones y dispositivos editoriales, Buenos Aires, Pontificia Universidad Católica Argentina, Pabellón de las Artes, [Educa], 2011.

---, Selected Writings, Daniel Owen \& Lisa Pearson (ed.), New York, Siglio/Ugly Duckling Press, 2018.

Di Ció, Mariana, "Los abecedarios reversibles de Mirtha Dermisache", 18 de septiembre de 2017, Blog, Web. Consultado el 10/03/2020.

Dworkin, Craig y Kenneth Goldsmith, Against Expression. An Anthology of Conceptual Writing, Evanston, Northwestern University Press, 2011.

Dworkin, Craig, Reading the Illegible, Evanston, Northwestern University Press, 2003.

Fajole, Florent, "Mirtha Dermisache: L'écriture autre, à elle-même", Centro de Estudios en Diseño y Comunicación, cuaderno 75, 2019, p. 83-97.

Fernández, Macedonio, "El plagio y la literatura infinita", Papeles de Buenos Aires no 3, 1944, p. 4.

---, "El zapallo que se hizo cosmos", Relato. Cuentos, poemas y misceláneas, Adolfo de Obieta (ed.), Buenos Aires, Corregidor, 1987, p. 51-54.

---, "Poema de trabajos de estudios de las estéticas de la siesta", Relato. Cuentos, poemas y misceláneas, Adolfo de Obieta (ed.), Buenos Aires, Corregidor, 1987, p. 133-137.

---, No toda es vigilia la de los ojos abiertos, Buenos Aires, Corregidor, 1990.

---, Papeles de Recienvenido y Continuación de la Nada, Buenos Aires, Corregidor, 1996.

---, Museo de la Novela de la Eterna, Adolfo de Obieta y Ana Camblong (ed.), Buenos Aires, ALLCA XX, 1996.

Ferrari, León, Retrospectiva. Obras 1954-2004, Buenos Aires, Centro Cultural Recoleta y Malba, 2005, p. 301-302.

Foucault, Michel, Las palabras y las cosas. Una arqueología de las ciencias humanas, México, Gallimard, 1968. Traducción de Elsa Cecilia Frost.

García, Francisca, “Leer lo no escrito: los grafismos de Mirtha Dermisache”, Poéticas del presente: perspectivas críticas sobre poesía hispánica contemporánea, Ottmar Ette y Julio Prieto (ed), Madrid, Iberoamericana-Vervuert, 2016, p. 259-271. 
García Canclini, Néstor, "El museo fuera de sí: León Ferrari”, La sociedad sin relato: antropología y estética de la inminencia, Buenos Aires, Katz Editores, 2010, p. 169-177.

Gilbert, Annette (ed.), Publishing as Artistic Practice, Berlín, Sternberg Press, 2016.

Giunta, Andrea, "Experimentalismo y supervivencia: consecuencias sociopolíticas del dibujo", Escribir las imágenes: ensayos sobre arte argentino y latinoamericano, Buenos Aires, Siglo XXI, 2011, p. 175-196.

Lefebvre, Henri, Critique de la vie quotidienne II. Fondements d'une sociologie de la quotidienneté, París, L'Arché, 1961.

Libertella, Héctor, Las sagradas escrituras, Buenos Aires, Sudamericana, 1993.

Montalbetti, Mario, Notas para un seminario sobre Foucault, Lima, FCE, 2018.

Moore, Barbara y John Hendricks, “The Page as Alternative Space, 1950-1969”, Artist's Books: A Critical Anthology and Sourcebook, Joan Lyons. Rochester (ed.), Visual Studies Workshop, 1985.

Novalis, Schriften, vol. 2, Paul Kluckhohn y Richard Samuel (ed.), Stuttgart, Kohlhammer, 1968. Perednik, Jorge Santiago (ed.), “Editorial”, XUL. Signo viejo y nuevo no 3, diciembre de 1981, p. 3. Pérez-Oramas, Luis, "León Ferrari and Mira Schendel: Tangled Alphabets", Leon Ferrari and Mira Schendel: Tangled Alphabets, Luis Pérez-Oramas (ed.), 2009, New York, The Museum of Modern Art, p. $12-45$.

Perloff, Marjorie, Unoriginal Genius: Poetry by Other Means in the New Century, Chicago, Chicago University Press, 2012.

Polaschegg, Andrea, "Enigmatische Aesthetik. Zur Kulturgeschichte Unlesbarer Schrift und ihrer künstlerischen Transformation", Schreiben als Ereignis: Künste und Kulturen der Schrift, Jutta Müller-Tamm et al. (ed.), Paderborn, Wilhelm Fink Verlag, 2018, p. 173-198.

Prieto, Julio, La escritura errante: ilegibilidad y políticas del estilo en Latinoamérica, Madrid, Iberoamericana-Vervuert, 2016.

---, "El etcétera en pintura", De la sombrología: seis comienzos en busca de Macedonio Fernández, Madrid, Iberoamericana-Vervuert, 2010, p. 61-85.

---, “Sobre ilegibilidad y malas escrituras en Hispanoamérica”, Ínsula nº 777, 2011, p. 1-2.

---, "La inquietante extrañeza de la autoría: contrapunto, fugas y espectros del origen en Macedonio y Borges", Historia crítica de la literatura argentina, vol. 8., Noé Jitrik y Roberto Ferro (ed.), Buenos Aires, Emecé, 2007, p. 475-504.

---, Desencuadernados: vanguardias ex-céntricas en el Río de la Plata, Rosario, Beatriz Viterbo, 2002.

Rancière, Jacques, Malaise dans l'esthétique, París, Galilée, 2004.

Rasula, Jed, "The Politics of, the Politics in", Politics and Poetic Value, Robert von Hallberg (ed.), Chicago, University of Chicago Press, 1987, p. 315-322

Rimmaudo, Annalisa y Giulia Lamoni, “Entrevista a Mirtha Dermisache”, agosto 2017 [publicada originalmente en Dermisache 2011], Blog, Web. Consultado el 10/03/2020.

Mirta Dermisache. Publicaciones y dispositivos editoriales. Buenos Aires, Pontificia Universidad Católica Argentina, 2011.

Rossi Landi, Ferruccio, El lenguaje como trabajo y como mercado, Caracas, Monte Ávila, 1972. Traducción de Italo Manzi. 
Schraenen, Guy, “Pour une approche des espaces alternatives”, Artefactum 8-11, 1985-

1986, p. 1-4.

Steiner, George, Lenguaje y silencio, Barcelona, Gedisa, 2003 [1976]. Traducción de Miguel Ultorio.

Ullán, José-Miguel, Agrafismos (Ondulaciones), Madrid, Instituto Cervantes, 2008.

--, Ondulaciones. Poesía reunida (1968-2007), Madrid, Galaxia Gutenberg, 2008.

Vecchio, Diego, Egocidios: Macedonio Fernández y la liquidación del yo, Rosario, Beatriz Viterbo, 2003.

\section{NOTES}

1. Hacia 1800, Novalis resume la situación así: "Pasó el tiempo en que el espíritu de Dios era legible. El sentido del mundo se ha perdido. Nos hemos quedado a solas con las letras" (1968: 594) [mi traducción].

2. Aquí y a lo largo del artículo distingo entre "significado" y "sentido" de acuerdo con la propuesta de Mario Montalbetti, que considera el "sentido" en cuanto "dirección" o vectorialidad no-significativa como rasgo específico de la poesía: "el sentido es ciego / el sentido es un vector que apunta hacia el afuera" (2018: 105).

3. Cabe traer a colación aquí la reflexión de Agamben sobre el concepto de "des-obramiento" [désoeuvrement] de Blanchot, al que atribuye un sentido específicamento político. Comentando la Metafísica de Aristóteles y la diferencia que éste establece entre potencia y acto (dynamis y energeia), Agamben piensa la relación entre poder constituyente y poder constituido, señalando que para que "la potencia no se desvanezca una y otra vez de forma inmediata en el acto [...] es necesario que pueda también no pasar al acto, que sea constitutivamente potencia de no (hacer o ser), o como dice Aristóteles, que sea asimismo impotencia (adynamia)" (1998: 63).

4. Tan sólo un reciente artículo de Fernando Bruno y un ensayo de Fernando Davis abordan lateralmente la cuestión, dedicándole sendos párrafos donde destacan algunas diferencias relevantes entre ambos proyectos (Bruno $2018 \mathrm{Web}$; Davis 2016). Otro trabajo reciente (Castro Godoy 2012) relaciona los proyectos de Ferrari y Dermisache con la tradición de las vanguardias latinoamericanas, sin entrar en una comparación analítica entre ambos.

5. En ese sentido es significativo el contraste entre la firma autorial legible que Ferrari inscribe en casi todos sus dibujos y el gesto de omisión de la firma en los libros de Dermisache, en los que suele incluir un volandero papelito desechable con una mínima información sobre la autora, acercándolos así a la anonimia. Incluso cuando incluyen algo que podría interpretarse como una firma autorial, como es el caso de sus dos primeros libros, se trata de una firma abstracta -tan ilegible como el resto de sus grafismos- en la que no es posible reconocer ningún nombre [fig. $14]$.

6. "La libertad que nos ofrecen sus grafismos", observa Felipe Becerra sobre Dermisache, "radica, precisamente, en despojarnos de nuestro saber leer, de nuestro saber escribir" (2018 Web).

7. Acerca de uno de esos libros infinitos, el narrador de "La biblioteca de Babel" comenta irónicamente: "El manejo de ese vademecum sedoso no sería cómodo: cada hoja aparente se desdoblaría en otras análogas; la inconcebible hoja central no tendría revés" (1989: 471).

8. Así en los proyectos colectivos en que participa en los años 60 , o en la parodia de la idolatría autorial que puede entre-leerse en Cuadro escrito: “[...] cuarenta centímetros cuadrados disimulados adrede en los varios metros que tiene este cuadro para que nadie perciba el lenguaje inaudible y reservarle la satisfacción a un sabio estudioso futuro de lo muerto que pondrá todo en claro y buscará agitado los huesos en mi cajón 
para hacer con ellos una especie de amuleto expuesto en un museo ante los prosternados feligreses rezadores por mi alma hoy viva pero escondida en Castelar" (2005: 292).

9. Así lo expone en la entusiasta carta que le escribe en 1971 a la joven Dermisache tras recibir algunas muestras de su trabajo por mediación del cineasta Hugo Santiago: “[...] quedé impresionado, no solamente por la gran calidad plástica de sus trazados (y esto no es indiferente) sino también, y sobre todo, por la extrema comprensión de problemas teóricos en relación con la escritura que supone su trabajo. Usted ha sabido producir un cierto número de formas, ni figurativas ni abstractas, pero que se podrían nombrar bajo el término de "escrituras ilegibles" -lo que significa proponer a sus lectores, no mensajes, y ni siquiera formas contingentes de la expresión, sino la idea, la esencia de la escritura" (Di Ció 2017 Web).

10. En ese sentido, las "cartas" ilegibles de Dermisache, sin ningún título o indicación circunstancial sobre sus condiciones de emisión o recepción -según su costumbre de no titular sus obras más allá de la denominación genérica: "libro", "carta”, “diario", "newsletter", etc.-, implican una interpelación política más fundamental que la Carta a un general de Ferrari (que, aunque ilegible, orienta en gran medida el sentido desde el título), de la misma manera que Sin título -un "dibujo escrito" que trabaja el mismo tipo de caligrafía imaginaria que las tres versiones de Carta a un general- o sus escrituras pseudoalfabéticas, y en general su obra "no significativa", nos interpelan de manera más decisiva que aquéllas o que las obras "comprometidas" o con un "mensaje" más o menos explícito [figs. 19 y 20].

\section{ABSTRACTS}

This article examines the illegible writings of Dermisache and Ferrari putting them in dialogue with the practices of aesthetic reduction that run throughout the modern tradition. Their "pseudo-alphabetisms" create productive illegibilities that I propose to analyze drawing on the notions of "bad writing" and "errant writing" investigated in previous works (Prieto 2011; 2016). The analysis focuses on exploring how these practices inscribe the "design" of writing, and considers the ethical, aesthetic and political dimension of the negative semiosis that emerges in the intermittence between the legible and the visible.

Este artículo propone una aproximación a las escrituras ilegibles de Dermisache y Ferrari situándolas en el marco de las prácticas de reducción estética que recorren la tradición moderna. Los "pseudoalfabetismos" que ponen en juego estos autores plantean ilegibilidades productivas que propongo analizar a partir de las nociones de "mala escritura" y "escritura errante" investigadas en previos trabajos (Prieto 2011; 2016). El análisis se concentra en explorar cómo estas prácticas trabajan el "dibujo" de la escritura, y cómo en la intermitencia entre lo legible y lo visible emerge la dimensión ética, estética y política de una semiosis de la falta.

Cet article propose une approche des écritures illisibles de Dermisache et Ferrari en les plaçant dans le cadre des pratiques de réduction esthétique qui traversent la tradition moderne. Leurs "pseudo-alphabétismes" proposent des illisibilités productives que j'essaye d'analyser en me basant sur les notions de "mauvaise écriture" et d' "écriture errante" étudiées dans des travaux 
antérieurs (Prieto 2011 : 2016). L'analyse s'attache à explorer comment ces pratiques travaillent le "dessin" de l'écriture, et comment dans l'intermittence entre le lisible et le visible émerge la dimension éthique, esthétique et politique d'une sémiose du manque.

INDEX

Mots-clés: illisibilité, langues imaginaires, politique de l'écriture, utopie, hétérotopie Keywords: illegibility, imaginary languages, politics of writing, utopia, heterotopia

Palabras claves: ilegibilidad, lenguajes imaginarios, política de la escritura, utopía, heterotopía

\section{AUTHOR}

JULIO PRIETO

Universität Potsdam

ju.prieto3@gmail.com 